\title{
Evolution of radiation-induced lattice defects in 20/25 Nb- stabilised austenitic stainless steel during in-situ proton irradiation
}

Dol:

10.1016/j.jnucmat.2018.11.019

\section{Document Version}

Accepted author manuscript

Link to publication record in Manchester Research Explorer

\section{Citation for published version (APA):}

Barcellini, C., Harrison, R., Dumbill, S., Donnelly, S. E., \& Jimenez-Melero, E. (2019). Evolution of radiationinduced lattice defects in $20 / 25 \mathrm{Nb}$-stabilised austenitic stainless steel during in-situ proton irradiation. Journal of Nuclear Materials, 514, 90-100. https://doi.org/10.1016/j.jnucmat.2018.11.019

\section{Published in:}

Journal of Nuclear Materials

\section{Citing this paper}

Please note that where the full-text provided on Manchester Research Explorer is the Author Accepted Manuscript or Proof version this may differ from the final Published version. If citing, it is advised that you check and use the publisher's definitive version.

\section{General rights}

Copyright and moral rights for the publications made accessible in the Research Explorer are retained by the authors and/or other copyright owners and it is a condition of accessing publications that users recognise and abide by the legal requirements associated with these rights.

\section{Takedown policy}

If you believe that this document breaches copyright please refer to the University of Manchester's Takedown Procedures [http://man.ac.uk/04Y6Bo] or contact uml.scholarlycommunications@manchester.ac.uk providing relevant details, so we can investigate your claim.

\section{OPEN ACCESS}




\title{
Manuscript Details
}

\section{Manuscript number}

Title

Article type
JNM_2018_1117_R1

Evolution of radiation-induced lattice defects in 20/25 Nb-stabilised austenitic stainless steel during in-situ proton irradiation

Full Length Article

\begin{abstract}
We have monitored in situ the lattice defect evolution induced by proton irradiation in $20 \mathrm{Cr}$-25Ni Nb-stabilised stainless steel, used as fuel cladding material in advanced gas-cooled reactors. At $420^{\circ} \mathrm{C}$, the damaged microstructure is mainly characterised by black spots and faulted a_0/3 111 Frank loops. Defect saturation is reached at only $0.1 \mathrm{dpa}$. In contrast, at $460^{\circ} \mathrm{C}$ and $500^{\circ} \mathrm{C}$ proton bombardment induces the formation of a mixture of a_0/3 111 Frank loops and perfect a_0/2 110 loops. These perfect loops evolve into dislocation lines that form a dense network. This transition coincides with the saturation in the dislocation loop size and number density at $0.8 \mathrm{dpa}\left(460^{\circ} \mathrm{C}\right)$ and $0.2 \mathrm{dpa}\left(500^{\circ} \mathrm{C}\right)$, respectively. The presence of a high density of dislocation loops and lines at those two temperatures causes a vacancy supersaturation in the matrix, leading to the formation of voids and stacking fault tetrahedra.
\end{abstract}

Manuscript category

Corresponding Author

Corresponding Author's Institution

Order of Authors

\section{Suggested reviewers}

Structural materials

chiara barcellini

University of Manchester

chiara barcellini, Robert Harrison, Simon Dumbill, Stephen Donnelly, Enrique Jimenez-Melero

Claude ALFONSO, Mercedes Hernandez-Mayoral, Takeshi Toyama, Frank Bergner 


\section{Submission Files Included in this PDF}

\section{File Name [File Type]}

Letter to the editor.docx [Cover Letter]

reply to reviewer comments.docx [Response to Reviewers]

Revised Manuscript with tracked changes.docx [Revised Manuscript with Changes Marked]

Highlights.docx [Highlights]

graphical abstract.jpeg [Graphical Abstract]

Manuscript.docx [Manuscript File]

FIG 1 .docx [Figure]

fig_2.docx [Figure]

fig_3.docx [Figure]

fig_4.docx [Figure]

fig_5.docx [Figure]

fig_6.docx [Figure]

fig_7.docx [Figure]

fig_8.docx [Figure]

fig_9.docx [Figure]

additional material.docx [Figure]

Tables.docx [Table]

To view all the submission files, including those not included in the PDF, click on the manuscript title on your EVISE Homepage, then click 'Download zip file'.

\section{Research Data Related to this Submission}

There are no linked research data sets for this submission. The following reason is given:

Data will be made available on request 
Dear editor,

Please find attached the resubmitted manuscript Ms. JNM_2018_1117 Barcellini et al. entitled 'Evolution of the radiation-induced lattice defects in 20/25 Nb-stabilised austenitic stainless steel during in-situ proton irradiation' which has been significantly revised on the basis of the comments received by the reviewers.

The detailed response to the reviewers' comments, together with the revised version of the manuscript, is attached. We would like to thank the reviewers for their time and effort in appraising the manuscript. The comments received were pertinent and helpful in improving the manuscript. All the points raised have been addressed and the manuscript has been amended accordingly. We believe that the revisions made adequately address the points raised and should therefore present no further obstacle to publication.

Yours sincerely,

Chiara Barcellini

Ms. Chiara Barcellini

Materials Performance Centre, School of Materials, University of Manchester, Oxford Road, Manchester, M13 9PL, United Kingdom

Tel.: +44 (0)7502577347, email: chiara.barcellini@postgrad.manchester.ac.uk 


\section{Reply Referee report on Ms. JNM_2018_1117 Barcellini et al.}

We thank the reviewers for carefully reading the manuscript and the useful comments. We have addressed all those comments, which we feel have improved the article quality. Detailed response:

\section{Reviewer 1}

1. Figure 1: Was anything done to confirm that the particles were $\mathrm{Nb}(\mathrm{C}, \mathrm{N})$ particles and not some other second phase particle or contamination of the sample?

We used STEM/EDX to confirm that the particles were $\mathrm{Nb}(\mathrm{C}, \mathrm{N})$. We have added a description of these particles in the results section, together with a new figure (Fig. 2) that shows two illustrative examples of STEM/EDX mapping of those particles.

2. Figure 2: Caption suggests that the images were captured on zone. Why were they not captured in a two beam condition? This would have given much clearer images.

Images were captured on zone and also in two beam condition at selected damage steps. Fig. 2 (now Fig. 3) displayed images on zone of the region of interest monitored during in situ irradiation. We have added examples of micrographs acquired in two beam condition in this figure.

3. Figure 5: It is difficult to tell what each image panel each portion of the caption refers to. I would suggest labelling a-h to avoid confusion.

We have added the labelling a-h in Fig. 5 (now Fig. 6) according to the reviewer's suggestion.

4. Figure 5: HAADF STEM images give only mass-thickness contrast and are not sensitive to stacking fault tetrahedra unless there is significant chemical segregation to them. It is more likely that these are medium or low angle ADF images. Is the camera length for the images known? This would help clarify.

In order to avoid confusion, the image has been substituted with a TEM/BF image.

5. Figure 7 and the associated discussion: The transformation of dislocation loops into lines is simply due to the loops coming into contact with the free surface and a segment escaping. That is, this transformation is a thin film effect and should not be presented as general behavior of these alloys under irradiation conditions. The discussion on the image should focus on loop growth behavior, not transformation from loop into line.

The average loop size saturates at $\sim 76 \mathrm{~nm}\left(500^{\circ} \mathrm{C}\right)$ and $\sim 50 \mathrm{~nm}\left(460^{\circ} \mathrm{C}\right)$, and saturation coincides with the transition of unfaulted loops into lines/networks. As the reviewer suggested, a segment of the loops may escape from the sample surface during the irradiation. 
However, the average loop size at saturation at both temperatures is significantly smaller than the estimated sample thickness of $110-140 \mathrm{~nm}$. Therefore, a significant fraction of the loops would transform into lines before they reach the sample surface. Besides that, the loop $\rightarrow$ line transition has also been reported in neutron-irradiated specimens, as mentioned in the introduction section. We have clarified this in the discussion section of the manuscript.

6. Diffraction vector or associated diffraction pattern should be included with electron micrographs.

We have added the diffraction vector in the case of two beam condition, and the diffraction pattern in the case of on zone micrographs.

7. It is not clear what 0.25 um refers to in the experimental section. Is it the particle size of the colloidal silica or the thickness of the sample?

It refers to the particle size of the colloidal silica suspension. We have clarified this in the experimental section.

8. Bottom of pg 6: Cut off used to separate high angle and low angle grain boundaries should be defined.

The threshold between high-angle and low-angle grain boundaries used in this work was $15^{\circ}$. This information is now indicated in the experimental and results sections.

\section{Reviewer 2}

1. Can authors explain why they used $40 \mathrm{KeV}$ protons performing irradiation? Are they aware that such low PKA energy is far lower than that from fast neutron irradiation?

We chose this proton beam energy because it was successful in simulating the microstructure of neutron-irradiated AGR cladding at $420^{\circ} \mathrm{C}$. This temperature corresponds to the peak temperature for the RIS phenomenon in AGR steel claddings. We have indicated this in the experimental section of the manuscript.

2. Authors mentioned in the introduction the water corrosion might be an issue since $\mathrm{Cr}$ depletion along GB may occur during irradiation, however there is nothing appeared in their results to look over the element change along GB. Did authors neglect it or it did not occur? We have observed chemical redistribution close to different defect sinks in this material and irradiation conditions. We have added some text in the results section. The detailed account of the RIS phenomenon will be the focus of a companion paper. 
3. Why did authors choose three specific temperatures from 420 to $500^{\circ} \mathrm{C}$ degrees, any particular reason? If the temperatures represent the variation from AGR inlet to outlet, please state it.

The selection of the irradiation temperatures in this study, namely $420^{\circ} \mathrm{C}, 460^{\circ} \mathrm{C}$ and $500^{\circ} \mathrm{C}$, was based on the fact that AGR cladding material experiences neutron-induced solute redistribution and sensitization in the temperature range from 350 to $520^{\circ} \mathrm{C}$, with a peak effect at $420^{\circ} \mathrm{C}$. This has now been mentioned explicitly in the introduction of the manuscript.

4. Authors discussed perfect loops and frank loops, as function of dose, temperature - I don't see any valuable outcomes, these are well documented in those references. What is new?

The novelty of this work lies in the relatively low damage range $(0.01 \mathrm{dpa}$ to $0.8 \mathrm{dpa})$ and high temperature range $\left(420^{\circ} \mathrm{C}\right.$ to $\left.500^{\circ} \mathrm{C}\right)$ explored. Very few studies have been published regarding the early stages of damage formation in austenitic stainless steels, being predominantly focused on damage levels close and above 1dpa where loop saturation has been reached. In most cases, those studies relate to radiation doses and temperatures relevant for LWRs, unfortunately not for AGRs. The British nuclear industry is facing the decommissioning of AGR plants, and the prolonged wet storage of spent AGR fuel relies on the resistance of sensitized AGR cladding to intergranular corrosion. The early formation and evolution of dislocation structures and other lattice defects at relevant environmental conditions is key for a successful RIS modelling campaign, and consequently to inform safety cases for spent fuel storage. This explanation has been added to the introduction of the manuscript.

5. The material was annealed at HT, then water quenched - can authors state their purpose of such processing?

The purpose of the heat treatment was to produce a fine dispersion of $\mathrm{Nb}(\mathrm{C}, \mathrm{N})$ in the recrystallized microstructure, so that the level of free interstitials $(C, N)$ in the matrix is kept to a minimum and the potential RIS phenomenon is in principle hindered. This has been added in the experimental section.

6. In figure 2 , at $500 \mathrm{C}$ experiments the area showing in the third row image looks very much bent, did author realize this large strain field could affect their results?

Fig. 2 (now Fig 3) shows the region of interest monitored during the entire in-situ irradiation experiment. However, at selected damage levels we also acquired micrographs of other sample regions. These additional micrographs were used at this temperature for the 
determination of the average loop size and number density. This has been clarified in the results section.

7. Did author ever think of using weak beam dark field imaging to capture those small defects, for example there could be tiny SFTs formed in 420C and $460 \mathrm{C}$ irradiation exams?

We used different imaging modes and could not find clear signs of small SFTs at the lower irradiation temperatures.

8. In figure 6, authors state they found this frank loop being unfault - I don't see why this is a frank loop at the first place. I would suggest a WBDF image may help to observe the SF fringes in the loop and gradual decay might indicate the unfault process.

We have provided evidence in the supplementary material of fringes inside a Frank loop. The fraction of observed Frank loops that undergo an unfaulting process is only $\sim 3 \%$ at $500^{\circ} \mathrm{C}$, and it was not observed at lower temperatures. This information has been added to the discussion section.

9. Regarding the Q1, I have to suggest authors redo the comparison between their $40 \mathrm{KeV}$ protons and fast neutrons, based on the PKA and cascades initiation.

Based on the reviewer's suggestion, we have improved the comparison between fast-neutron and low-energy proton damage in the discussion session, taking into consideration the energy-dependent recoil events in each case. 


\section{Evolution of radiation-induced lattice defects in $20 / 25 \mathrm{Nb}$-stabilised austenitic stainless steel during in-situ proton irradiation}

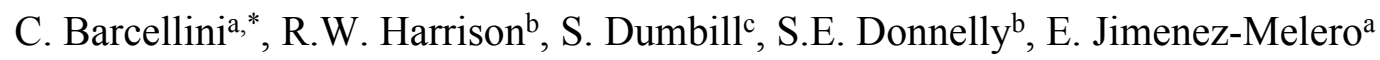

aMaterials Performance Centre, School of Materials, The University of Manchester,

Manchester M13 9PL, UK

${ }^{b}$ School of Computing and Engineering, University of Huddersfield, Huddersfield HD1 3DH, $U K$

${ }^{b}$ National Nuclear Laboratory, Sellafield, Seascale CA20 1PG, UK

*Corresponding author

Email: chiara.barcellini@postgrad.manchester.ac.uk

University of Manchester

School of Materials

Materials Performance Centre

Oxford Road

Manchester

M13 9PL

United Kingdom 


\section{Abstract}

We have monitored in situ the lattice defect evolution induced by proton irradiation in $20 \mathrm{Cr}$ $25 \mathrm{Ni} \mathrm{Nb}$-stabilised stainless steel, used as fuel cladding material in advanced gas-cooled reactors. At $420^{\circ} \mathrm{C}$, the damaged microstructure is mainly characterised by black spots and faulted $\frac{a_{0}}{3}\langle 111\rangle$ Frank loops. Defect saturation is reached at only $0.1 \mathrm{dpa}$. In contrast, at $460^{\circ} \mathrm{C}$ and $500^{\circ} \mathrm{C}$ proton bombardment induces the formation of a mixture of $\frac{a_{0}}{3}\langle 111\rangle$ Frank loops and perfect $\frac{a_{0}}{2}\langle 110\rangle$ loops. These perfect loops evolve into dislocation lines that form a dense network. This transition coincides with the saturation in the dislocation loop size and number density at $0.8 \mathrm{dpa}\left(460^{\circ} \mathrm{C}\right)$ and $0.2 \mathrm{dpa}\left(500^{\circ} \mathrm{C}\right)$, respectively. The presence of a high density of dislocation loops and lines at those two temperatures causes a vacancy supersaturation in the matrix, leading to the formation of voids and stacking fault tetrahedra.

Keywords: austenitic stainless steel, in-situ proton irradiation, dislocation analysis, transmission electron microscopy, advanced gas-cooled reactor 


\section{Introduction}

The fuel claddings currently used in the UK Advanced Gas-cooled Reactors (AGR) are made of $\mathrm{Nb}$-stabilized austenitic stainless steel containing $20 \mathrm{wt} . \% \mathrm{Cr}$ and $25 \mathrm{wt} . \% \mathrm{Ni}$. The selection of this steel grade is based on its excellent resistance to water corrosion due primarily to the high content of chromium [1], and to its thermal creep resistance in oxidizing environments [2-5]. A stabilizing heat treatment at $930^{\circ} \mathrm{C}$ aims to trap the carbon and nitrogen atoms in a fine dispersion of $\mathrm{Nb}(\mathrm{C}, \mathrm{N})$ particles, prior to the cladding lifetime in the reactor. Those particles aid to control the austenite grain size and increase the creep resistance at the reactor core temperatures $\left(350-700^{\circ} \mathrm{C}[6]\right)$, and also prevent the formation of detrimental chromium-containing carbides and nitrides at grain boundaries during reactor operations [7,8][9]. However, during the service life in the reactor core at elevated temperatures and neutron fluxes, the cladding material experiences $\mathrm{Cr}$ depletion at/near grain boundaries, enhancing the material's susceptibility to intergranular corrosion attacks when the spent fuel elements are subsequently stored in caustic-dosed water ponds. This phenomenon is termed Radiation-Induced Sensitization (RIS), and affects grain boundaries of those fuel elements which have been exposed to AGR neutron fluxes in the temperature range of 350$520^{\circ} \mathrm{C}$, with a peak effect at $\sim 420^{\circ} \mathrm{C}[6,10,11]$. RIS represents a potential hazard for the interim storage of AGR irradiated fuel elements in water ponds [12], therefore there is a growing interest in developing a mechanistic understanding of radiation damage in AGR cladding material and to what extend the damage would impact on the material's resistance to RIS.

The redistribution of solute atoms in the vicinity of grain boundaries is interpreted as stemming from the biased coupling of solute fluxes with the diffusion of radiation-induced vacancies or self-interstitial atoms towards defect sinks such as grain boundaries [13]. This 
phenomenon has also been observed in other steel grades [14-18], and the variety of measured solute profiles can not only be ascribed to different irradiation conditions, but also to the geometry of the grain boundary itself [17-19]. The point defects induced by neutron bombardment can recombine or form lattice defects of higher dimensionality after the displacement cascade, depending on the irradiation temperature. This defect activity alters the number and strength of defect sinks in the microstructure, and consequently the point defect diffusion and solute redistribution. Throughout the years, different studies of the microstructural evolution induced by neutron irradiation have been published for several austenitic steel grades, with a focus on the 300 series of austenitic stainless steels widely employed in the nuclear industry [20-23]. In these steels, neutron bombardment induces the formation of $\frac{a_{0}}{3}\langle 111\rangle$ Frank loops [20,21,24]. They are often reported as 'black-spot' damage at low irradiation temperatures, due to their size being smaller than 2-3nm [25-28]. They grow in diameter with increasing irradiation temperature, and when they reach a size in the range of $\sim 50 \mathrm{~nm}$ to $100 \mathrm{~nm}$, they can unfault forming perfect dislocation loops with a $\frac{a_{0}}{2}\langle 110\rangle$ Burgers vector [21]. Perfect loops are more mobile than Frank loops, and the interaction of those perfect loops with one another may give rise to dislocation networks. Radiation-induced voids [20,29-31], stacking fault tetrahedra (SFT) [32] and radiation-induced, -enhanced or modified precipitates $[20,25,29,33]$ can also be observed in neutron-irradiated austenitic stainless steels.

The microstructural characterisation of the radiation-induced damage evolution is a fundamental step in understanding the mechanisms inducing solute segregation or depletion close to lattice defects in $20 \mathrm{Cr}-25 \mathrm{Ni}$ stainless steel. Traditional RIS modelling in this material did not include the competing effect of other defect sinks in the microstructure that are generated simultaneously during irradiation [34-37]. In this study, we have monitored in-situ 
the early stages of the lattice damage evolution caused by proton bombardment in the microstructure of recrystallized $20 \mathrm{Cr}-25 \mathrm{Ni} \mathrm{Nb}$-stabilized stainless steel, namely at relatively low damage levels from 0.01 to $0.8 \mathrm{dpa}$ and in the temperature range of $420-500^{\circ} \mathrm{C}$, using a transmission electron microscope (TEM) coupled to an ion accelerator [38,39]. In the past, intense proton beams have been used successfully to simulate the neutron damage in other nuclear steel grades with minimal sample activation [40,41], [42]. A limited number of studies have been published regarding the early stages of damage formation in austenitic stainless steels, being predominantly focused on damage levels close and above 1dpa where loop saturation has been reached, and on temperatures relevant instead for Light Water Reactors [21][28]. The selection of the specific irradiation temperatures in this study, namely $420^{\circ} \mathrm{C}, 460^{\circ} \mathrm{C}$ and $500^{\circ} \mathrm{C}$, was based on the fact that AGR cladding material experiences neutron-induced solute redistribution and sensitization in the temperature range from 350 to $520^{\circ} \mathrm{C}$, with a peak effect at $420^{\circ} \mathrm{C}$ [6]. The early formation and evolution of dislocation structures and other lattice defects at relevant environmental AGR conditions is key for a successful RIS modelling campaign, and consequently to inform safety cases for spent fuel storage. The analysis of the local chemical composition profiles at the grain boundaries and other defect sinks of the AGR cladding material will be presented in a companion paper.

\section{Experimental}

The as-received AGR cladding material was in the form of a $55 \mathrm{~cm}$ long tube with transverse ribs on the outer surface. It had an outer diameter of $1.5 \mathrm{~cm}$ and an average wall thickness of $0.4 \mathrm{~cm}$. Its chemical composition is provided in Table 1 . After removing the external ribs, we extracted samples with a size of $2.5 \times 2.5 \mathrm{~cm}^{2}$ and subjected them to a recrystallization annealing treatment at $930^{\circ} \mathrm{C}$ for $40 \mathrm{~min}$ in inert atmosphere, followed by water quenching. The purpose of this heat treatment was to produce a fine dispersion of $\mathrm{Nb}(\mathrm{C}, \mathrm{N})$ in the recrystallized microstructure [9], so that the level of free interstitials $(\mathrm{C}, \mathrm{N})$ in the matrix is 
kept to a minimum and the potential RIS phenomenon is in principle hindered. The heattreated samples were mechanically ground and polished using in the last step a colloidal silica suspension with a particle size of $0.25 \mu \mathrm{m}$. The structural characterization was performed using a FEI Quanta 650 equipped an electron backscattered diffraction (EBSD) detector. The EBSD data processing was performed using the MTEX software [43]. In the EBSD data analysis, the threshold between high-angle and low-angle grain boundaries was $15^{\circ}[44,45]$. We also performed TEM imaging and analysis of the samples using a FEI Tecnai G2 20 microscope equipped with a Gatan CCD camera. In this case, 3mm-diameter TEM discs were extracted from the heat-treated material and electropolished using an electrolyte of 95 vol. \% methanol - 5 vol. $\%$ perchloric acid $(60 \%)$ at a temperature of $-25^{\circ} \mathrm{C}$.

The in-situ proton irradiations were performed at the Microscope and Ion Accelerator for Materials Investigation - 2 system (MIAMI-2 system), located at the University of Huddersfield, UK. The samples were mounted in a high-temperature double-tilt holder and placed inside a $300 \mathrm{kV}$ Hitachi H-9500 TEM with a spatial resolution of $0.14 \mathrm{~nm}$, equipped with a $\mathrm{LaB}_{6}$ electron source and a Gatan OneView digital camera with 16 megapixels and up to $300 \mathrm{fps}$ video. The TEM is installed at the end of a beam line connected to an ion accelerator, capable of producing proton beams with energies up to $350 \mathrm{keV}$. The proton beam enters the microscope chamber at $18.7^{\circ}$ with respect to the electron beam. We used a proton beam energy of $40 \mathrm{keV}$, and the Bragg peak position would be at $\sim 200 \mathrm{~nm}$ from the sample surface exposed to the incoming proton beam, based on SRIM simulations [46]. We chose this proton beam energy because it was successful in simulating the microstructure of neutron-irradiated AGR cladding at $420^{\circ} \mathrm{C}$ (see discussion section). This temperature corresponds to the peak temperature for the RIS phenomenon in AGR steel claddings. We performed three irradiation experiments using equivalent steel samples at the selected temperatures of $420^{\circ} \mathrm{C}, 460^{\circ} \mathrm{C}$ and $500^{\circ} \mathrm{C}$, and at a proton flux of $\sim 8 x 10^{13}$ ions $\cdot \mathrm{cm}^{-2} \cdot \mathrm{s}^{-1}$, 
corresponding to a dose rate of $\sim 2 \cdot 10^{-4} \mathrm{dpa} / \mathrm{s}$. Images were captured on zone during in-situ irradiation. Additionally at selected damage steps we probed other regions of interest in the sample, and also recorded TEM data in two beam condition. After each irradiation, the sample was characterized ex-situ using an FEI Tecnai G2 20 microscope. The invisibility criterion was used to determine the Burgers vector $\vec{b}$ of the observed dislocations, whereas their nature was assessed by the inside-outside contrast method [47]. The loop size and number density were determined using bright-field images. We used as loop diameter the longest dimension, since under some irradiation conditions the dislocation loops observed in the TEM deviates from circular shape. The foil thickness has been derived from the fringes spacing in convergent beam electron diffraction patterns (CBED) [48]. The foil thickness values obtained were in the range of $110-140 \mathrm{~nm}$. These thickness values are lower than the Bragg peak position of the $40 \mathrm{keV}$ proton beam. The damage levels reported in this study correspond to the average values through the sample thickness. Voids present in the microstructure were observed using the out-of-focus imaging technique in bright-field mode [47]. Further analysis of the radiation damage were conducted ex-situ using a FEI Talos F200A TEM/STEM microscope, equipped with a X-FEG field emission source (TEM information limit of $0.12 \mathrm{~nm}$, point resolution of $0.25 \mathrm{~nm}$ and STEM high angle annular dark field resolution of $0.16 \mathrm{~nm}$ ). This microscope was also used to acquire STEM/EDX maps of the second phase particles observed in the as-recrystallised and proton-irradiated specimens, and the recorded data was then processed using the FEI Velox software.

\section{Results}

The steel microstructure after the $40 \mathrm{~min}$ heat treatment at $930^{\circ} \mathrm{C}$ is shown in Fig. 1. This high-temperature heat treatment followed by water quenching was chosen in order to mimic the stabilising heat treatment performed on the AGR claddings before entering their service life in the reactor core, as briefly explained above. The microstructure obtained is 
characterised by smooth recrystallised grains with an average diameter of $\sim 10 \mu \mathrm{m}$. The inverse pole figure colour map in Fig. 1a reveals that the recrystallised grains do not exhibit a marked preferred orientation. During the heat treatment, a high number of annealing twin boundaries is produced, accounting for $\sim 45 \%$ of the total grain boundary length. In addition, we also observed $\sim 36 \%$ of high angle grain boundaries (with a misorientation angle $\theta \geq 15^{\circ}$ ) and only $\sim 19 \%$ of low angle grain boundaries $\left(\theta<15^{\circ}\right)$. Moreover, a dispersion of fine of second phase particles precipitates heterogeneously in the matrix, both intergranular (Fig. 1c) and intragranular (Fig. 1d), and in many cases forming particle clusters. STEM/EDX confirmed that those particles present in the microstructure after the $930^{\circ} \mathrm{C}$ annealing are $\mathrm{Nb}$ rich (see Fig 2a), and therefore they have identified as $\mathrm{Nb}(\mathrm{C}, \mathrm{N})$. We have also detected larger $\mathrm{Nb}(\mathrm{C}, \mathrm{N})$ particles already present in the as-received material, and often surrounded by a network of dislocation lines; see Fig. 1e. These larger particles are also $\mathrm{Nb}(\mathrm{C}, \mathrm{N})$ and no segregation of other solute elements was detected (see Fig. 2b).

The evolution of the microstructure during proton irradiation at three different temperatures can be followed in Fig. 3. The early stages of radiation-induced lattice damage in this steel are characterised by the presence of dislocation structures at the three irradiation temperatures. However, the evolution of those structures with increasing damage level varies significantly with temperature. At $420^{\circ} \mathrm{C}$, black spots smaller than $2 \mathrm{~nm}$ are visible in the TEM images of the microstructure at $0.03 \mathrm{dpa}$, together with a number of larger faulted Frank loops with a Burgers vector of $\frac{a_{0}}{3}\langle 111\rangle$. These microstructural features dominate the radiation-induced microstructure up to $0.5 \mathrm{dpa}$; see first row of Fig. 3. The size distribution at a damage level of $0.05 \mathrm{dpa}$, considering both the black spots and the Frank loops, is presented in Fig. 4. The average defect size increases from $\sim 9 \mathrm{~nm}$ at $0.03 \mathrm{dpa}$ to $\sim 12 \mathrm{~nm}$ at $0.05 \mathrm{dpa}$, concomitantly with an increase in number density from $8.1 \times 10^{16} \mathrm{~cm}^{-3}$ to $3.2 \times 10^{17} \mathrm{~cm}^{-3}$ respectively, see Fig. 5. At a damage level of $0.1 \mathrm{dpa}$ and higher, the damage in the 
microstructure becomes very dense and uniform, reaching the resolution limit of the imaging technique used during the in-situ observation. For this reason we were not able to characterise the damage at $420^{\circ} \mathrm{C}$ above this damage level. At $0.1 \mathrm{dpa}$, only identifiable defects were taken into account and the loop parameters for $0.1 \mathrm{dpa}$ in Fig. 5 may be less accurate than at lower damage levels. Due to the highly dense damage observed in the microstructure at $0.5 \mathrm{dpa}$ and no signs of other types of dislocation structures, we did not proceed with the proton irradiation beyond this damage level at a temperature of $420^{\circ} \mathrm{C}$.

At higher irradiation temperatures, a longer incubation period or critical damage level is required for the first signs of radiation damage to be observed in the microstructure; see middle and bottom rows in Fig. 3. The first black spots are visible at $0.05 \mathrm{dpa}$ both at $460^{\circ} \mathrm{C}$ and $500^{\circ} \mathrm{C}$, in contrast with $0.03 \mathrm{dpa}$ at $420^{\circ} \mathrm{C}$. Furthermore, the first resolvable Frank loops are observed at $0.1 \mathrm{dpa}$ at $460^{\circ} \mathrm{C}$ and at $0.2 \mathrm{dpa}$ at $500^{\circ} \mathrm{C}$, respectively, together with a number of unfaulted $\frac{a_{0}}{2}\langle 110\rangle$ loops already present at somewhat lower damage levels. Examples of the defect size distribution at representative damage levels at $460^{\circ} \mathrm{C}$ and $500^{\circ} \mathrm{C}$ are shown in Fig. 4, and the average loop diameter and number density as a function of damage level are show in Fig. 5. Comparatively at the same damage level, the lattice defects become larger and less dense with increasing irradiation temperature. Moreover, the average diameter increases steadily with damage level at $460^{\circ} \mathrm{C}$, reaching saturation at $0.8 \mathrm{dpa}$. In contrast, at $500^{\circ} \mathrm{C}$ a plateau is reached in the average size already at $0.2 \mathrm{dpa}$, after a rapid increase from $\sim 14 \mathrm{~nm}$ to $\sim 76 \mathrm{~nm}$ between $0.05 \mathrm{dpa}$ and $0.2 \mathrm{dpa}$. At this damage level, dislocation networks appear in the microstructure and gradually replace the dislocation loops as the main feature of radiation-induced damage. At $460^{\circ} \mathrm{C}$ this transition from loops into networks is delayed to higher damage levels. At this lower temperature and a damage level of $0.8 \mathrm{dpa}$, loop saturation is reached, and a few dislocation tangles start to form. However, the dislocation loops remain the main feature of the radiation-induced damage. The ratio between unfaulted 
and faulted loops remains close to $\sim 0.8$ at $460^{\circ} \mathrm{C}$ and at $0.8 \mathrm{dpa}$ faulted Frank loops are still observed in the damaged microstructure. However, at $500^{\circ} \mathrm{C}$ that ratio is not constant, but decreases at increasing dose from $\sim 0.9$ at $0.2 \mathrm{dpa}$ to $\sim 0.4$ at $0.5 \mathrm{dpa}$ when a significant dislocation network is observed in the TEM images.

Fig. 6 displays examples of radiation-induced dislocation loops at $460^{\circ} \mathrm{C}$ and $500^{\circ} \mathrm{C}$, together with other lattice defects observed in the microstructure at relatively high damage levels. At $460^{\circ} \mathrm{C}$ the loops are relatively small and often present geometrical shapes, such as hexagons and rhombuses. Those loops evolve in less regular shapes at higher damage levels. Besides that, edge-on loops (green arrows in Fig. 6b) and black spots are observed during the whole range of damage levels explored. The edge-on loops present their habit plane parallel to the direction of the electron beam, and they are therefore observed on BF TEM images as lines, instead of close circuits. At $500^{\circ} \mathrm{C}$, the dislocation loops are mainly circular or elliptical in shape, and in some cases small loops are observed to form and grow inside larger loops. Additionally, radiation-induced voids have been observed both at $460^{\circ} \mathrm{C}$ and $500^{\circ} \mathrm{C}$ in this study, but not at $420^{\circ} \mathrm{C}$. The average void diameter increases with temperature from $\sim 3.7 \mathrm{~nm}$ (distribution standard deviation of $1 \mathrm{~nm}$ ) to $\sim 6.1 \mathrm{~nm}$ (distribution standard deviation of $1.5 \mathrm{~nm}$ ) at $0.8 \mathrm{dpa}$, whereas the number density decreases from $6.3 \cdot 10^{15} \mathrm{~cm}^{-3}$ to $4.0 \cdot 10^{15} \mathrm{~cm}^{-3}$, respectively. At $500^{\circ} \mathrm{C}$ stacking fault tetrahedra (SFT) are also observed in the microstructure. They are characterised at $0.8 \mathrm{dpa}$ by an average diameter of $\sim 32 \mathrm{~nm}$, with a standard deviation of $6 \mathrm{~nm}$, and a number density of $9.2 \cdot 10^{13} \mathrm{~cm}^{-3}$.

Local changes in chemical composition were detected at grain boundaries, dislocations and particle/matrix interfaces at the three irradiation temperatures at the highest damage level of this experiment, namely $0.5 \mathrm{dpa}$ at $420^{\circ} \mathrm{C}$, and $0.8 \mathrm{dpa}$ at both $460^{\circ} \mathrm{C}$ and $500^{\circ} \mathrm{C}$. For all those types of defect sinks, we observed the depletion of $\mathrm{Cr}, \mathrm{Fe}$ and to a lower 
extend of $\mathrm{Mn}$, together with the local enrichment in $\mathrm{Ni}$ and $\mathrm{Si}$. The results of the chemical characterisation close to lattice defects will be presented in a companion paper.

\section{Discussion}

The defect evolution and resultant morphologies induced by proton bombardment in $20 \mathrm{Cr}$ $25 \mathrm{Ni} \mathrm{Nb}$-stabilized stainless steel depend on the selected irradiation temperature. At $420^{\circ} \mathrm{C}$, the microstructure observed by TEM up to a damage level of $0.5 \mathrm{dpa}$ is characterized by a high density of black spots and a number of $\frac{a_{0}}{3}\langle 111\rangle$ Frank loops. The radiation-induced damage develops at the relatively low damage level of $0.03 \mathrm{dpa}$ and reaches saturation at only $0.1 \mathrm{dpa}$. The damage evolution at $420^{\circ} \mathrm{C}$ in this steel grade resembles the microstructure reported for other solution-annealed stainless steels irradiated with neutrons at temperatures below $300^{\circ} \mathrm{C}[20,21,49]$. The radiation-induced microstructure, both in the present study and in the case of neutron irradiation, is dominated by the so-called black spots. They are small defect clusters which cannot be resolved in diffraction contrast mode in TEM. They can be both clusters of vacancies, interstitials or impurities, or already well-defined voids or dislocation loops of either nature [22,28,32]. Although in the past these black spots were thought to be predominately of vacancy nature [25-27], more recent studies suggest that they are a mixture of very small vacancy and interstitial Frank loops [28], [50].

At the higher irradiation temperatures of $460^{\circ} \mathrm{C}$ and $500^{\circ} \mathrm{C}$, the microstructure is characterized by the presence of a mixed population of faulted interstitial $\frac{a_{0}}{3}\langle 111\rangle$ Frank loops and unfaulted $\frac{a_{0}}{2}\langle 110\rangle$ dislocation loops, formed after an incubation period or critical damage level. In this temperature range, both types of dislocation loops originate from the growth of clusters of self-interstitial atoms. In fcc materials two cluster configurations of selfinterstitial atoms are possible: $\langle 100\rangle$ dumbbells and $\langle 110\rangle$ crowdions [13]. Once formed, both types of dislocation loops grow with increasing damage level; see loop labelled 'A' in 
Fig. 7. When the Frank loops reached a critical size, they can transform into unfaulted loops. A necessary condition for the unfaulting reaction to take place is the decrease of the loop energy. Based on the energy associated with the two different loop configurations, i.e. faulted and unfaulted, we obtain the following inequality [24]:

$\gamma_{S F E}>\frac{\mu b^{2}}{3 \pi r_{l}}\left[\frac{2-v}{2(v-1)}\right] \ln \left\{\frac{4 r_{l}}{r_{c}}-2\right\}$

where $\gamma_{S F E}\left(35 \mathrm{mJm}^{-2}\right)$ is the stacking fault energy, $\mu(82 \mathrm{GPa})$ is its shear modulus, $b$ $(0.2 \mathrm{~nm})$ is the modulus of the Burgers vector associated with the Frank loop, $r_{l}$ is the radius of the dislocation loop, $v(0.3)$ is the Poisson ratio and $r_{c}(0.5 \mathrm{~nm})$ is the radius of the dislocation core. The data in parenthesis for the aforementioned parameters in the case of stainless steel are taken from ref. [51]. Solving eq. (1) for the loop radius $r_{l}$, we obtained that the minimum loop radius for the faulted-to-unfaulted reaction is $\sim 80 \mathrm{~nm}$. Therefore, the reaction is only energetically favorable for loops whose diameter is $\sim 160 \mathrm{~nm}$ or higher, most likely limited by the sample thickness in one of the loop dimensions. In this study, we found significant percentages of loops that satisfy this condition only at $500^{\circ} \mathrm{C}$, e.g. $12 \%$ at $0.3 \mathrm{dpa}$. Moreover, in order for the reaction to happen, Frank $\frac{a_{0}}{3}[111]$ faulted loops must react with Shockley $\frac{a_{0}}{6}[11 \overline{2}]$ partial dislocations. Therefore, the unfaulting sequence would be [52]:

$\frac{a_{0}}{6}[11 \overline{2}]+\frac{a_{0}}{3}[111]=\frac{a_{0}}{2}[110]$

The Shockley partial dislocation must nucleate within the Frank dislocation loops for the reaction to occur. Due to the energy condition and the need for Shockley partial nucleation, the faulted-to-unfaulted reaction has seldom been observed in the in-situ irradiation experiments discussed in this paper. An example of this process taking place at $500^{\circ} \mathrm{C}$ is shown in Fig. 7, where loop B with a diameter of $\sim 190 \mathrm{~nm}$ at $0.25 \mathrm{dpa}$ unfaults when 
increasing the damage level to $0.29 \mathrm{dpa}$. In contrast, the ratio between unfaulted and faulted loops remains constant at $460^{\circ} \mathrm{C}$ during the whole irradiation. The fraction of observed Frank loops that undergo an unfaulting process is only $\sim 3 \%$ at $500^{\circ} \mathrm{C}$, and it was not observed at lower temperatures.

Furthermore, perfect dislocation loops can evolve into lines with increasing dose. Perfect loops and especially dislocation lines are glissile, and can move more easily than the sessile Frank loops [53]. The movement of dislocations leads to the occurrence of dislocation tangles, which constitute the last stage of radiation damage evolution in austenitic stainless steels $[20,21,40]$. The formation of tangles or networks occurs both at $460^{\circ} \mathrm{C}$ and $500^{\circ} \mathrm{C}$, as shown as an illustrative example in Fig. 8 for the damage level of 0.8dpa. A higher damage level is required for the dislocation lines to appear in the microstructure at $460^{\circ} \mathrm{C}$, and even at 0.8dpa only a reduced number of dislocation lines can be observed amongst the loops (see Fig. 8). At $500^{\circ} \mathrm{C}$ the first dislocation lines are already visible at $0.2 \mathrm{dpa}$, when the average loop diameter attains saturation at $\sim 76 \mathrm{~nm}$. At this higher temperature, the ratio between unfaulted and faulted loop decreases with the increasing damage level beyond $0.2 \mathrm{dpa}$, due to the transition of a larger number of perfect loops into dislocation lines. Furthermore, the dislocation network formed from the mobile dislocation lines constitute an additional sink for self-interstitial atoms [21], therefore limiting the formation of new dislocation loops and the resultant loop number density at higher damage levels. The average loop size saturates at $\sim 76 \mathrm{~nm}\left(500^{\circ} \mathrm{C}\right)$ and $\sim 50 \mathrm{~nm}\left(460^{\circ} \mathrm{C}\right)$, and saturation coincides with the transition of unfaulted loops into lines/networks. A segment of the loops may escape from the sample surface during the irradiation. However, the average loop size at saturation at both temperatures is significantly smaller than the estimated sample thickness of 110-140nm. Therefore, a significant fraction of the loops would transform into lines before they reach the sample 
surface. Besides that, the loop $\rightarrow$ line transition has also been reported in neutron-irradiated specimens, as mentioned in the introduction section.

Besides the formation of dislocation structures induced by proton bombardment, voids have also been observed at $0.8 \mathrm{dpa}$ for $460^{\circ} \mathrm{C}$ and $500^{\circ} \mathrm{C}$, see Fig. 6 . The average void size increases with irradiation temperature, whereas their number density decreases. In contrast, voids are not observed in the irradiated microstructure at $420^{\circ} \mathrm{C}$ in the studied range of damage levels. The presence of voids has been reported in other austenitic steel grades irradiated with neutrons at temperatures above $300^{\circ} \mathrm{C}[20,29,30]$, [31]. Supersaturation of vacancies is known to be the driving force for void nucleation and growth [13], and different nucleation mechanisms have been proposed, such as nucleation on pre-existing sites in the microstructures, formed directly in the displacement spikes and even via homogeneous nucleation [31]. Voids are not stable below a critical size [54] and would shrink by vacancy emission [55]. During neutron irradiation He atoms can formed by nuclear transmutation from nickel $[18,19]$. The presence of transmuted or implanted gas atoms, such as $\mathrm{He}$ or $\mathrm{H}$, are reported to help stabilise small voids against their collapse into vacancy loops at the very early stages in void formation and swelling [29]. In the present study, no He implantation has been performed or produced by transmutation reactions, and the predicted Bragg peak position of the proton beam (200nm) exceeds the thickness of the TEM foils used (110$140 \mathrm{~nm})$. At $460^{\circ} \mathrm{C}$ and $500^{\circ} \mathrm{C}$ formation of perfect interstitial loops, and their evolution into a high density of dislocation lines, precede the formation of voids. Fig. 6 displays examples of voids having formed close to dislocation lines at $460^{\circ} \mathrm{C}$, and close to a twin boundary at $500^{\circ} \mathrm{C}$. These two lattice defects would absorb interstitial atoms preferentially, yielding a local supersaturation of vacancies in the matrix to form voids [56]. The void distribution at $500^{\circ} \mathrm{C}$ is more homogeneous than at $460^{\circ} \mathrm{C}$, and a small number of square-shaped voids are also observed at $500^{\circ} \mathrm{C}$ (see blue circle in Fig 6g). 
At the highest irradiation temperature, i.e. $500^{\circ} \mathrm{C}$, stacking fault tetrahedra are also observed at $0.8 \mathrm{dpa}$, but in a relatively low number density with respect to the other radiationinduced defects, see Fig. 6h. SFTs are composed of intrinsic on the fo on the $\{111\}$ planes with a stair-rod $\frac{a_{0}}{6}\langle 110\rangle$ dislocation along the edges of the tetrahedron [57]. Based on energy theoretical calculations [58], SFTs should be the most stable vacancy-cluster morphology in stainless steel up to 4000 vacancies. The presence of SFTs in the microstructure of model Febased alloys has been reported in the literature, both at irradiation temperatures lower than $300^{\circ} \mathrm{C}[59]$ and higher than $550^{\circ} \mathrm{C}[60,61]$, where they compete with voids as the dominant intrinsic lattice defect [32]. However, SFTs have been very rarely observed in commercial grade austenitic stainless steels [62], probably due to the presence of impurities and other alloying elements in small quantities that can strongly affect the stacking fault energy (SFE) [63] and also change the evolution of the displacement cascade by binding with vacancies [64]. Various nucleation mechanisms have been proposed throughout the years for SFTs produced during irradiation [32]: SFTs can originate from the dissociation of vacancy-type Frank loops [65], or from small triangular-shaped vacancy nuclei by vacancy absorption [66], through a mechanism of void collapse [67], or directly in the displacement cascade as proposed by [20,21] and confirmed by molecular dynamic simulations [50,68], [69]. The absence of SFTs at $420^{\circ} \mathrm{C}$ and $460^{\circ} \mathrm{C}$ in the present study may be due to the lack of vacancy supersaturation in the matrix, due to the fact that voids are formed preferentially. At $500^{\circ} \mathrm{C}$, dislocation tangles appear already at $0.2 \mathrm{dpa}$ and they absorb interstitials preferentially, loading to a higher vacancy concentration in the matrix than at $460^{\circ} \mathrm{C}$, which can evolve into voids or SFTs. It has to be pointed out that the SFT observed in this study are significantly larger than those reported for other irradiated austenitic stainless steel grades. The average dimension is $\sim 32 \mathrm{~nm}$ with a standard deviation of the size distribution of $6 \mathrm{~nm}$, against an average dimension of around $10 \mathrm{~nm}$ reported in the literature [30]. An average SFT size of 
$20 \mathrm{~nm}$, with a maximum size approaching $30 \mathrm{~nm}$, has been measured in a model austenitic alloy irradiated with neutrons at $550^{\circ} \mathrm{C}$ and $600^{\circ} \mathrm{C}$ (peak exposure of $4.7 \mathrm{dpa}$ ) [52]. In the present study, the absence of SFT smaller than $25 \mathrm{~nm}$ might indicate that these type of defects do not nucleate continuously in $20 \mathrm{Cr}-25 \mathrm{Ni}$ austenitic stainless steel at $500^{\circ} \mathrm{C}$. This observation seems to preclude the direct nucleation in the displacement cascade, in favor of the nucleation by vacancy clustering after supersaturation of vacancies has been generated in the matrix. However, we cannot exclude that SFTs form by the dissociation of vacancy-type Frank loops [65].

The direct comparison of the results obtained in our in-situ proton irradiation experiment with those obtained by in-reactor neutron irradiation is particularly challenging for $20 \mathrm{Cr}-25 \mathrm{Ni} \mathrm{Nb}$-stabilised stainless steel, due to the limited and fragmented nature of the neutron data available. The majority of neutron irradiation studies are primarily focused on the RIS detection and quantification [6,10,70-73], and unfortunately only limited data is available about the lattice defects induced by neutron irradiation [6,10], despite their importance in understanding and predicting RIS profiles in AGR cladding materials. In Fig. 9, we compare our proton irradiation results with the existing data on the neutron-induced microstructure of this steel at the relatively low damage level of 2.2dpa. At this damage level, significant corrosion attacks were detected at the grain boundaries of the matrix after perfoming an accelerated Strauss test [6]. The neutron-induced dislocation density reported for the temperature of $418^{\circ} \mathrm{C}$ is $4 \cdot 10^{14} \mathrm{~m}^{-2}$ [6], which is very close to the dislocation density measured in this study at $0.2 \mathrm{dpa}$ at $460^{\circ} \mathrm{C}$. Unfortunately, the dislocation density was not reported for the sample irradiated with neutrons at $460^{\circ} \mathrm{C}$ at a damage level of $2.2 \mathrm{dpa}$ [10]. However, its microstructure does not resemble the one observed in this study for a protonirradiated sample at $500^{\circ} \mathrm{C}$ and a damage level of $0.4 \mathrm{dpa}$. A shift in temperature has been proposed in the literature to compensate the difference in dose rate between neutron and 
proton irradiations, for an equivalent damage level (assuming a recombination-dominated steady state), according to the expression [74]:

$$
T_{2}=T_{1}+\frac{\frac{k_{B} T_{1}^{2}}{E_{m}^{v}+2 E_{f}^{v}} \ln \left\{\frac{\phi_{2}}{\phi_{1}}\right\}}{1-\frac{k_{B} T_{1}}{E_{m}^{v}+2 E_{f}^{v}} \ln \left\{\frac{\phi_{2}}{\phi_{1}}\right\}}
$$

where $T_{2}$ is the proton irradiation temperature, $T_{1}$ is the neutron irradiation temperature, $k_{B}$ is the Boltzmann constant, $\phi_{2}$ is the proton dose rate $\left(\sim 2 \cdot 10^{-4} \mathrm{dpa} / \mathrm{s}\right.$ in this study $), \phi_{1}$ is the neutron dose rate $\left(4 \cdot 10^{-8} \mathrm{dpa} / \mathrm{s}\right.$ in AGR reactors [37]), $E_{m}^{v}$ is the vacancy migration energy (1.3eV [13]), and $E_{f}^{v}$ the vacancy formation energy (1.9 eV [13]). In this case, Eq. (3) predicts a temperature shift from $418^{\circ} \mathrm{C}$ to $500^{\circ} \mathrm{C}$ and from $460^{\circ} \mathrm{C}$ to $630^{\circ} \mathrm{C}$, in order to compensate for the difference in approx. four orders of magnitude in dose rate for the same damage level. Our comparative results indicate that a higher temperature would be needed in proton irradiations, in order to compare with the damage induced by neutron irradiations, but at lower damage levels. With the present $40 \mathrm{keV}$ proton irradiation experiment we were able to replicate the damaged microstructure of those AGR claddings most affected by RIS after inreactor neutron irradiation $\left(\sim 2 \mathrm{dpa}\right.$ at $\left.\sim 420^{\circ} \mathrm{C}\right)$ by proton irradiation at $460^{\circ} \mathrm{C}$ for a damage level of $0.2 \mathrm{dpa}$, and also the damaged microstructures reported at low temperatures in other austenitic steel grades by selecting an irradiation temperature of $420^{\circ} \mathrm{C}$. , However, we could not replicate the expected temperature shift. This might be due to the differences in the recoil spectra between low-energy light ions such as the proton beam used and the fission neutrons present in the reactor core [75]. The proton beam used in the present study had an energy of $40 \mathrm{keV}$, hence the majority of the damage is produced by low-energy recoil events [76]. On the other hand, in the case of in-reactor neutron irradiation, nearly all lattice defects are generated in cascade by high-energy recoils [77]. The actual number of defects surviving 
after the cascade cooling phase determines the final damage produced in the crystalline structure [13]. Defects produced in relatively large clusters, as in the case of neutron bombardment, have a lower probability to survive the cascade than singularly produced defects. The higher efficiency in the damage production of protons may therefore be the reason behind the fact that we observed a similar proton-damaged microstructure to the reported neutron-induced microstructures in the AGR cladding steel, but at a lower damage level.

\section{Conclusions}

We have performed an in-situ proton irradiation of $20 \mathrm{Cr}-25 \mathrm{Ni} \mathrm{Nb}$-stabilised stainless steel at three selected temperatures with increasing damage levels up to 0.8dpa. This austenitic stainless steel is currently being used as fuel cladding in $\mathrm{AGR}$ reactors. At $420^{\circ} \mathrm{C}$, the radiation-induced damage is dominated by black spots and $\frac{a_{0}}{3}\langle 111\rangle$ Frank loops, and saturates at the relatively low damage level of $0.1 \mathrm{dpa}$. In contrast, at $460^{\circ} \mathrm{C}$ and $500^{\circ} \mathrm{C}$ the damaged microstructure is characterised by a mixed population of Frank loops and perfect $\frac{a_{0}}{2}\langle 110\rangle$ loops at low damage levels, which evolve into a dislocation network at $\geq 0.8 \mathrm{dpa}\left(460^{\circ} \mathrm{C}\right)$ and $\geq 0.2 \mathrm{dpa}\left(500^{\circ} \mathrm{C}\right)$, respectively. The radiation-induced dislocation loops present a lower average size and a higher number density at lower irradiation temperatures. The loop saturation is reached at a higher damage level for a lower temperature, and seems to coincide with the occurrence of a dislocation network. The high density of perfect dislocation loops and lines in the form of a network gives rise to a vacancy supersaturation in the matrix, and consequently to the formation of voids and stacking fault tetrahedra in the microstructure.

\section{Acknowledgments}

We acknowledge the Engineering and Physical Sciences Research Council (EPRSC) for providing funding for this project through the DISTINCTIVE grant (EP/L014041/1), and also 
for the development of the MIAMI-2 Facility (EP/M028283/1) and access via the UK

National Ion Beam Centre. We would also like to thank Dr. S. Walters from the National Nuclear Laboratory for providing the starting material.

\section{References}

[1] R.C. Lobb, H.E. Evans, A determination of the chromium concentration for 'healing' layer formation during the oxidation of chromium-depleted 20cr-25ni-nb stainless steel, Corros. Sci. 24 (1984) 385-396. doi:10.1016/0010-938X(84)90065-9.

[2] S. Nategh, P.J. Goodhew, Z.C. Szkopiak, Microstructural stability during creep of a niobium-stabilized austenitic steel, Acta Metall. 29 (1981) 1299-1308. doi:10.1016/0001-6160(81)90021-3.

[3] G. Knowles, The Creep Strength of 20\%Cr- $25 \% \mathrm{Ni}-\mathrm{Nb}$ Steel Containing Controlled Particle Dispersions, Met. Sci. (1977) 117-122.

[4] H.E. Evans, D.A. Hilton, Structure and properties of nitrided stainless steel fuel cladding for use in advanced gas-cooled reactors, Nucl. Energy. 18 (1979) 33-38. https://inis.iaea.org/search/search.aspx?orig_q=RN:10470696 (accessed July 22, 2018).

[5] R.C. Lobb, R.C. Ecob, Creep rupture properties of oxidised 20\% Cr austenitic stainless steels, Mater. Sci. Technol. 6 (1990) 73-80. doi:10.1179/mst.1990.6.1.73.

[6] C. Taylor, The Formation of Sensitised Microstructures during the Irradiation of CAGR Fuel Pin Cladding, in: D.I.R. Norris (Ed.), Radiation-Induced Sensitisation Stainl. Steel, Berkeley Nuclear Laboratories, 1986.

[7] V. Ramaswamy, D.R.F. West, NbC Precipitation in 20\%Cr-25\%Ni-1\%Nb Austenitic Steel, J. Iron Steel Inst. 208 (1970) 391-394.

[8] T. Sourmail, Precipitation in creep resistant austenitic stainless steel, Mater. Sci. Technol. 17 (2001). 
[9] C. Barcellini, S. Dumbill, E. Jimenez-Melero, Isothermal annealing behaviour of nuclear grade 20Cr-25Ni austenitic stainless steel, Mater. Charact. 145 (2018) 303311. doi:10.1016/j.matchar.2018.08.057.

[10] D.I.R. Norris, C. Baker, C. Taylor, J.M. Titchmarsh, Radiation-Induced Segregation in 20Cr/25Ni/Nb Stainless Steel, ASTM STP 1125, 1992.

[11] D.I.R. Norris, C. Baker, J.M. Titchmarsh, Compositionl Profiles at Grain Boundaries in $20 \% \mathrm{Cr} / 25 \% \mathrm{Ni} / \mathrm{Nb}$ Steinless Steel, in: D.I.R. Norris (Ed.), Radiation-Induced Sensitisation Stainl. Steel, Berkeley Nuclear Laboratories, 1987: p. 87.

[12] NDA Corporate report, Oxide Fuels Preferred Option, SMS/TS/C2-OF/001, 2012.

[13] G.S. Was, Fundamentals of Radiation Materials Science: Metals and Alloys, Springer, 2007.

[14] T.R. Allen, G.S. Was, E.A. Kenik, The effect of alloy composition on radiationinduced segregation in Fe/Cr/Ni alloys, J. Nucl. Mater. 244 (1997) 278-294. doi:10.1016/S0022-3115(96)00744-1.

[15] T.R. Allen, J.T. Busby, G.S. Was, E.A. Kenik, On the mechanism of radiation-induced segregation in austenitic Fe--Cr--Ni alloys, J. Nucl. Mater. 255 (1998) 44-58. doi:http://dx.doi.org/10.1016/S0022-3115(98)00010-5.

[16] T.R. Allen, G.S. Was, The effect of ordering on radiation-induced segregation in austenitic iron- and nickel-base alloys, in: Eff. Radiat. Mater. 18th Int. Symp., ASTM, 1999.

[17] K.G. Field, L.M. Barnard, C.M. Parish, J.T. Busby, D. Morgan, T.R. Allen, Dependence on grain boundary structure of radiation induced segregation in a $9 \mathrm{wt} . \%$ Cr model ferritic/martensitic steel, J. Nucl. Mater. 435 (2013) 172-180. doi:10.1016/J.JNUCMAT.2012.12.026.

[18] T.S. Duh, J.J. Kai, F.R. Chen, L.H. Wang, Numerical simulation modeling on the 
effects of grain boundary misorientation on radiation-induced solute segregation in 304 austenitic stainless steels, J. Nucl. Mater. 294 (2001) 267-273.

[19] T.S. Duh, J.J. Kai, F.R. Chen, Effects of grain boundary misorientation on solute segregation in thermally sensitized and proton-irradiated 304 stainless steel, J. Nucl. Mater. 283-287 (2000) 198-204. doi:10.1016/S0022-3115(00)00255-5.

[20] P.J. Maziasz, Overview of microstructural evolution in neutron-irradiated austenitic stainless steels, J. Nucl. Mater. 205 (1993) 118-145. doi:10.1016/00223115(93)90077-C.

[21] S.J. Zinkle, P.J. Maziasz, R.E. Stoller, Dose dependence of the microstructural evolution in neutron-irradiated austenitic stainless steel, J. Nucl. Mater. 206 (1993) 266-286. doi:10.1016/0022-3115(93)90128-L.

[22] S.M. Bruemmer, E.P. Simonen, P.M. Scott, P.L. Andresen, G.S. Was, J.L. Nelson, Radiation-induced material changes and susceptibility to intergranular failure of lightwater-reactor core internals, J. Nucl. Mater. 274 (1999) 299-314. doi:10.1016/S00223115(99)00075-6.

[23] A.F. Rowcliffe, S.J. Zinkle, J.F. Stubbins, D.J. Edwards, D.J. Alexander, Austenitic stainless steels and high strength copper alloys for fusion components, J. Nucl. Mater. 258-263 (1998) 183-192. doi:10.1016/S0022-3115(98)00333-X.

[24] B.T. Kelly, Irradiation damage to solids, 1st ed., Oxford; New York : Pergamon Press, 1966.

[25] T.S. Byun, E.H. Lee, J.D. Hunn, Plastic deformation in 316LN stainless steel characterization of deformation microstructures, J. Nucl. Mater. 321 (2003) 29-39. doi:10.1016/S0022-3115(03)00195-8.

[26] E.H. Lee, J.D. Hunn, T.S. Byun, L.K. Mansur, Effects of helium on radiation-induced defect microstructure in austenitic stainless steel, J. Nucl. Mater. 280 (2000) 18-24. 
doi:10.1016/S0022-3115(00)00038-6.

[27] N. Hashimoto, E. Wakai, J.P. Robertson, Relationship between hardening and damage structure in austenitic stainless steel 316LN irradiated at low temperature in the HFIR, J. Nucl. Mater. 273 (1999) 95-101. doi:10.1016/S0022-3115(99)00009-4.

[28] D.J. Edwards, E.P. Simonen, S.M. Bruemmer, Evolution of fine-scale defects in stainless steels neutron-irradiated at $275^{\circ} \mathrm{C}$, J. Nucl. Mater. 317 (2003) 13-31. doi:10.1016/S0022-3115(03)00002-3.

[29] T.R. Allen, J.I. Cole, C.L. Trybus, D.L. Porter, H. Tsai, F. Garner, E.A. Kenik, T. Yoshitake, J. Ohta, The effect of dose rate on the response of austenitic stainless steels to neutron radiation, J. Nucl. Mater. 348 (2006) 148-164. doi:10.1016/J.JNUCMAT.2005.09.011.

[30] J.I. Cole, T.R. Allen, Microstructural changes induced by post-irradiation annealing of neutron-irradiated austenitic stainless steels, J. Nucl. Mater. 283-287 (2000) 329-333. doi:10.1016/S0022-3115(00)00072-6.

[31] D.I.R. Norris, Voids in irradiated metals (Part I), Radiat. Eff. 15 (1972) 1-22. https://doi.org/10.1080/00337577208230470.

[32] R. Schibli, R. Schäublin, On the formation of stacking fault tetrahedra in irradiated austenitic stainless steels - A literature review, J. Nucl. Mater. 442 (2013) S761-S767. doi:10.1016/J.JNUCMAT.2013.05.077.

[33] D.J. Edwards, E.P. Simonen, F.A. Garner, L.R. Greenwood, B.M. Oliver, S.M. Bruemmer, Influence of irradiation temperature and dose gradients on the microstructural evolution in neutron-irradiated 316SS, J. Nucl. Mater. 317 (2003) 3245. doi:10.1016/S0022-3115(03)00003-5.

[34] A.D. Marwick, Segregation in irradiated alloys: The inverse Kirkendall effect and the effect of constitution on void swelling, J. Phys. F Met. Phys. 8 (1978) 1849. 
http://stacks.iop.org/0305-4608/8/i=9/a=008.

[35] H. Wiedersich, P.R. Okamoto, N.Q. Lam, A theory of radiation-induced segregation in concentrated alloys, J. Nucl. Mater. 83 (1979) 98-108.

doi:http://dx.doi.org/10.1016/0022-3115(79)90596-8.

[36] S. Watanabe, H. Takahashi, Discriminant of RIS in multi-component alloys, J. Nucl. Mater. 208 (1994) 191-194. doi:10.1016/0022-3115(94)90211-9.

[37] J.M. Perks, A.D. Marwick, C.A. English, Fundamental Aspects of radiation-induced Segregation in Fe-Cr-Ni Alloys, in: D.I.R. Norris (Ed.), Radiation-Induced Sensitisation Stainl. Steel, Berkeley Nuclear Laboratories, 1986.

[38] J.A. Hinks, A review of transmission electron microscopes with in situ ion irradiation, Nucl. Instruments Methods Phys. Res. Sect. B Beam Interact. with Mater. Atoms. 267 (2009) 3652-3662. doi:10.1016/J.NIMB.2009.09.014.

[39] S. Ishino, A review of in situ observation of defect production with energetic heavy ions, J. Nucl. Mater. 251 (1997) 225-236. doi:10.1016/S0022-3115(97)00247-X.

[40] G.S. Was, J.T. Busby, T. Allen, E.A. Kenik, A. Jensson, S.M. Bruemmer, J. Gan, A.D. Edwards, P.M. Scott, P.L. Andreson, Emulation of neutron irradiation effects with protons: validation of principle, J. Nucl. Mater. 300 (2002) 198-216. doi:http://dx.doi.org/10.1016/S0022-3115(01)00751-6.

[41] G.S. Was, T.R. Allen, J.T. Busby, J. Gan, D. Damcott, D. Carter, M. Atzmon, E.A. Kenik, Microchemistry and microstructure of proton-irradiated austenitic alloys: toward an understanding of irradiation effects in LWR core components, J. Nucl. Mater. 270 (1999) 96-114. doi:10.1016/S0022-3115(98)00897-6.

[42] J. Gan, G.S. Was, Microstructure evolution in austenitic $\mathrm{Fe}-\mathrm{Cr}-\mathrm{Ni}$ alloys irradiated with protons: comparison with neutron-irradiated microstructures, J. Nucl. Mater. 297 (2001) 161-175. doi:10.1016/S0022-3115(01)00615-8. 
[43] F. Bachmann, R. Hielscher, H. Schaeben, Texture Analysis with MTEX -- Free and Open Source Software Toolbox, in: Texture Anisotropy Polycrystals III, Trans Tech Publications, 2010: pp. 63-68.

[44] R.E. Stoller, M.B. Toloczko, G.S. Was, A.G. Certain, S. Dwaraknath, F.A. Garner, On the use of $\{$ SRIM $\}$ for computing radiation damage exposure, Nucl. Instruments Methods Phys. Res. Sect. B Beam Interact. with Mater. Atoms. 310 (2013) 75-80. doi:http://dx.doi.org/10.1016/j.nimb.2013.05.008.

[45] M.L. Jenkins, Characterisation of radiation-damage microstructures by TEM, J. Nucl. Mater. 216 (1994) 124-156. doi:http://dx.doi.org/10.1016/0022-3115(94)90010-8.

[46] D. Delille, R. Pantel, E. Van Cappellen, Crystal thickness and extinction distance determination using energy filtered $\{\mathrm{CBED}\}$ pattern intensity measurement and dynamical diffraction theory fitting, Ultramicroscopy. 87 (2001) 5-18. doi:http://dx.doi.org/10.1016/S0304-3991(00)00067-X.

[47] F.J. Humphreys, Quantitative metallography by electron backscattered diffraction, J. Microsc. 195 (1999) 170-185. http://dx.doi.org/10.1046/j.1365-2818.1999.00578.x.

[48] F.J. Humphreys, Review Grain and subgrain characterisation by electron backscatter diffraction, J. Mater. Sci. 36 (2001) 3833-3854. https://doi.org/10.1023/A:1017973432592.

[49] H.R. Brager, J.L. Straalsund, Defect development in neutron irradiated type 316 stainless steel, J. Nucl. Mater. 46 (1973) 134-158. doi:10.1016/0022-3115(73)901311.

[50] R. Stoenescu, R. Schaeublin, D. Gavillet, N. Baluc, Mechanical propertiesmicrostructure correlation in neutron irradiated heat-affected zones of austenitic stainless steels, J. Nucl. Mater. 362 (2007) 287-292. doi:10.1016/J.JNUCMAT.2007.01.251. 
[51] G.S. Was, T.R. Allen, Radiation damage from different particle types, in: B.P.U. Kurt E. Sickafus Eugene A. Kotomin (Ed.), Radiat. Eff. Solids, Springer Netherlands, 2007.

[52] H. Tanigawa, A. Kohyama, Y. Katoh, A modeling of radiation induced microstructural evolution under applied stress in austenitic alloys, J. Nucl. Mater. 239 (1996) 80-84. doi:10.1016/S0022-3115(96)00414-X.

[53] D.J. Hull, Derek \& Bacon, Introduction to dislocations, 5th ed., ButterworthHeinemann, 2011.

[54] K.C. Russell, Nucleation of voids in irradiated metals, Acta Metall. 19 (1971) 753758. doi:10.1016/0001-6160(71)90131-3.

[55] K.C. Russell, Nucleation of voids in irradiated metals. II. The general case, Scr. Metall. 6 (1972) 209-214. doi:10.1016/0036-9748(72)90169-X.

[56] D.I.R. Norris, The growth of voids in nickel in a high-voltage electron microscope, Philos. Mag. A J. Theor. Exp. Appl. Phys. 23 (1971) 135-152. doi:10.1080/14786437108216368.

[57] M. Kiritani, Story of stacking fault tetrahedra, Mater. Chem. Phys. 50 (1997) 133-138. doi:10.1016/S0254-0584(97)80250-7.

[58] S.J. Zinkle, L.E. Seitzman, W.G. Wolfer, S.J. Zinkle, W.G. Wolfer, I. Energy calculations for pure metals, Philos. Mag. A Phys. Condens. Matter, Struct. Defects Mech. Prop. 55 (1987) 111-125. doi:10.1080/01418618708209803.

[59] M. Horiki, S. Arai, Y. Satoh, M. Kiritani, Identification of the nature of small point defect clusters in neutron irradiated $\mathrm{Fe}-16 \mathrm{Ni}-15 \mathrm{Cr}$ by means of electron irradiation, $\mathrm{J}$. Nucl. Mater. 255 (1998) 165-173. doi:10.1016/S0022-3115(98)00033-6.

[60] R.E. Stoller, G.R. Odette, Observations of stacking-fault tetrahedra in an austenitic alloy after high-temperature neutron irradiation, Philos. Mag. A. 58 (1988) 523-532. doi:10.1080/01418618808210428. 
[61] R.E. Stoller, G.R. Odette, The effects of helium implantation on microstructural evolution in an austenitic alloy, J. Nucl. Mater. 154 (1988) 286-304. doi:10.1016/0022-3115(88)90365-0.

[62] Y. Dai, X. Jia, J.C. Chen, W.F. Sommer, M. Victoria, G.S. Bauer, Microstructure of both as-irradiated and deformed 304L stainless steel irradiated with $800 \mathrm{MeV}$ protons, J. Nucl. Mater. 296 (2001) 174-182. doi:10.1016/S0022-3115(01)00565-7.

[63] S. Lu, Q.-M. Hu, B. Johansson, L. Vitos, Stacking fault energies of Mn, Co and Nb alloyed austenitic stainless steels, Acta Mater. 59 (2011) 5728-5734. doi:https://doi.org/10.1016/j.actamat.2011.05.049.

[64] C.A. English, B.L. Eyre, K. Shoaib, T.M. Williams, Vacancy cluster damage in type 316 stainless steel irradiated with Cr+ ions, J. Nucl. Mater. 58 (1975) 220-226. doi:10.1016/0022-3115(75)90110-5.

[65] J. Silcox, P.B. Hirsch, Direct observations of defects in quenched gold, Philos. Mag. 4 (1959) 72-89. doi:10.1080/14786435908238228.

[66] G. Czjzek, A. Seeger, S. Mader, Die Stabilität von Stapelfehlertetraedern in abgeschreckten kubisch-flächenzentrierten Metallen und Legierungen, Phys. Status Solidi. 2 (1962) 558-565. doi:10.1002/pssb.19620020505.

[67] B.P. Uberuaga, R.G. Hoagland, A.F. Voter, S.M. Valone, Direct Transformation of Vacancy Voids to Stacking Fault Tetrahedra, Phys. Rev. Lett. 99 (2007).

[68] K. Nordlund, F. Gao, Formation of stacking-fault tetrahedra in collision cascades, Appl. Phys. Lett. 74 (1999) 2720-2722. doi:10.1063/1.123948.

[69] Z. Yao, M.J. Caturla, R. Schäublin, Study of cascades damage in Ni by MD with different interatomic potentials, J. Nucl. Mater. 367-370 (2007) 298-304. doi:10.1016/J.JNUCMAT.2007.03.136.

[70] M.A. Ashworth, D.I.R. Norris, I.P. Jones, Radiation-Induced Segregation in 
Fe/20Cr/25Ni/Nb Based Austenitic Stainless Steel, J. Nucl. Mater. 189 (1992) 289302.

[71] D.I.R. Norris, C. Baker, J.M. Titchmarsh, A study of radiation-induced sensitusation in 20/25/Nb steel by compositional profile measurements at grain boundaries, in: B.N.E. Society (Ed.), Mater. Nucl. React. Core Appl., 1987.

[72] J.M. Titchmarsh, I.A. Vatter, Measurement of Radiation-induced Segregation Profiles by High Spatial Resolution Electron Microscopy, in: D.I.R. Norris (Ed.), RadiationInduced Sensitisation Stainl. Steel, Berkeley Nuclear Laboratories, 1986.

[73] T.M. Williams, R.M. Boothby, J.M. Titchmarsh, Compositional Redistribution in Irradiated Austenitic Steels and Consequent Changes in Microstructures, in: D.I.R. Norris (Ed.), Radiation-Induced Sensitisation Stainl. Steel, Berkeley Nuclear Laboratories, 1986.

[74] L.K. Mansur, Theory of transitions in dose dependence of radiation effects in structural alloys, J. Nucl. Mater. 206 (1993) 306-323. doi:http://dx.doi.org/10.1016/0022-3115(93)90130-Q.

[75] C. Abromeit, Aspects of simulation of neutron damage by ion irradiation, J. Nucl. Mater. 216 (1994) 78-96. doi:10.1016/0022-3115(94)90008-6.

[76] R.S. Averback, Atomic displacement processes in irradiated metals, J. Nucl. Mater. 216 (1994) 49-62. doi:10.1016/0022-3115(94)90006-X.

[77] L.R. Greenwood, Neutron interactions and atomic recoil spectra, J. Nucl. Mater. 216 (1994) 29-44. doi:10.1016/0022-3115(94)90004-3. 


\section{Highlights}

1. Proton-irradiated cladding steel develops high dislocation density at low dpa levels

2. Proton-induced $\frac{a_{0}}{3}\langle 111\rangle$ Frank loops and black spots saturate at only $0.1 \mathrm{dpa}$ at $420^{\circ} \mathrm{C}$

3. The ratio of unfaulted to faulted loops remains close to 0.8 up to $0.8 \mathrm{dpa}$ at $460^{\circ} \mathrm{C}$

4. At $500^{\circ} \mathrm{C}$ the unfaulted dislocation loops transit into dislocation lines at $0.2 \mathrm{dpa}$

5. Voids are present at $0.8 \mathrm{dpa}$ with average size of $3.7 \mathrm{~nm}\left(460^{\circ} \mathrm{C}\right)$ and $6.1 \mathrm{~nm}\left(500^{\circ} \mathrm{C}\right)$ 


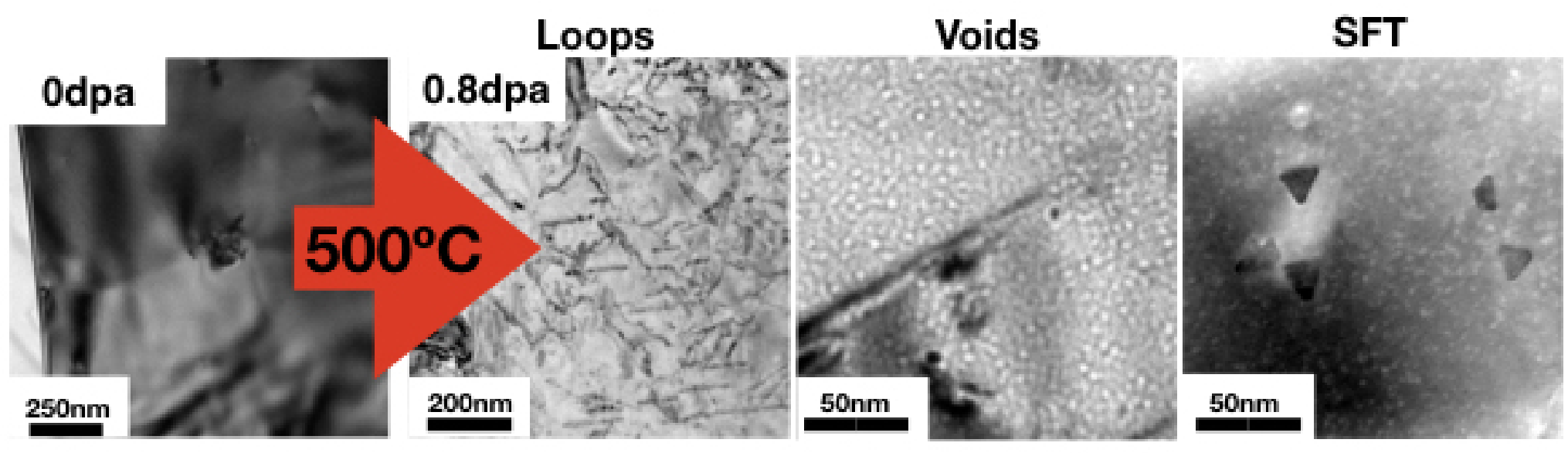




\section{Evolution of radiation-induced lattice defects in $20 / 25 \mathrm{Nb}$-stabilised austenitic stainless steel during in-situ proton irradiation}

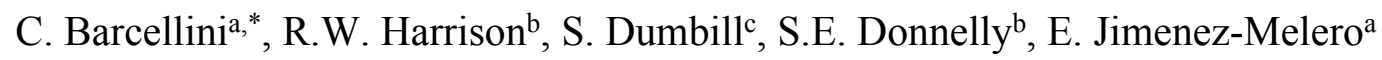

aMaterials Performance Centre, School of Materials, The University of Manchester,

Manchester M13 9PL, UK

${ }^{b}$ School of Computing and Engineering, University of Huddersfield, Huddersfield HD1 3DH, $U K$

${ }^{b}$ National Nuclear Laboratory, Sellafield, Seascale CA20 1PG, UK

*Corresponding author

Email: chiara.barcellini@postgrad.manchester.ac.uk

University of Manchester

School of Materials

Materials Performance Centre

Oxford Road

Manchester

M13 9PL

United Kingdom 


\section{Abstract}

We have monitored in situ the lattice defect evolution induced by proton irradiation in $20 \mathrm{Cr}$ $25 \mathrm{Ni} \mathrm{Nb}$-stabilised stainless steel, used as fuel cladding material in advanced gas-cooled reactors. At $420^{\circ} \mathrm{C}$, the damaged microstructure is mainly characterised by black spots and faulted $\frac{a_{0}}{3}\langle 111\rangle$ Frank loops. Defect saturation is reached at only $0.1 \mathrm{dpa}$. In contrast, at $460^{\circ} \mathrm{C}$ and $500^{\circ} \mathrm{C}$ proton bombardment induces the formation of a mixture of $\frac{a_{0}}{3}\langle 111\rangle$ Frank loops and perfect $\frac{a_{0}}{2}\langle 110\rangle$ loops. These perfect loops evolve into dislocation lines that form a dense network. This transition coincides with the saturation in the dislocation loop size and number density at $0.8 \mathrm{dpa}\left(460^{\circ} \mathrm{C}\right)$ and $0.2 \mathrm{dpa}\left(500^{\circ} \mathrm{C}\right)$, respectively. The presence of a high density of dislocation loops and lines at those two temperatures causes a vacancy supersaturation in the matrix, leading to the formation of voids and stacking fault tetrahedra.

Keywords: austenitic stainless steel, in-situ proton irradiation, dislocation analysis, transmission electron microscopy, advanced gas-cooled reactor 


\section{Introduction}

The fuel claddings currently used in the UK Advanced Gas-cooled Reactors (AGR) are made of $\mathrm{Nb}$-stabilized austenitic stainless steel containing $20 \mathrm{wt} . \% \mathrm{Cr}$ and $25 \mathrm{wt} . \% \mathrm{Ni}$. The selection of this steel grade is based on its excellent resistance to water corrosion due primarily to the high content of chromium [1], and to its thermal creep resistance in oxidizing environments [2-5]. A stabilizing heat treatment at $930^{\circ} \mathrm{C}$ aims to trap the carbon and nitrogen atoms in a fine dispersion of $\mathrm{Nb}(\mathrm{C}, \mathrm{N})$ particles, prior to the cladding lifetime in the reactor. Those particles aid to control the austenite grain size and increase the creep resistance at the reactor core temperatures $\left(350-700^{\circ} \mathrm{C}[6]\right)$, and also prevent the formation of detrimental chromium-containing carbides and nitrides at grain boundaries during reactor operations [7,8][9]. However, during the service life in the reactor core at elevated temperatures and neutron fluxes, the cladding material experiences $\mathrm{Cr}$ depletion at/near grain boundaries, enhancing the material's susceptibility to intergranular corrosion attacks when the spent fuel elements are subsequently stored in caustic-dosed water ponds. This phenomenon is termed Radiation-Induced Sensitization (RIS), and affects grain boundaries of those fuel elements which have been exposed to AGR neutron fluxes in the temperature range of 350$520^{\circ} \mathrm{C}$, with a peak effect at $\sim 420^{\circ} \mathrm{C}[6,10,11]$. RIS represents a potential hazard for the interim storage of AGR irradiated fuel elements in water ponds [12], therefore there is a growing interest in developing a mechanistic understanding of radiation damage in AGR cladding material and to what extend the damage would impact on the material's resistance to RIS.

The redistribution of solute atoms in the vicinity of grain boundaries is interpreted as stemming from the biased coupling of solute fluxes with the diffusion of radiation-induced vacancies or self-interstitial atoms towards defect sinks such as grain boundaries [13]. This 
phenomenon has also been observed in other steel grades [14-18], and the variety of measured solute profiles can not only be ascribed to different irradiation conditions, but also to the geometry of the grain boundary itself [17-19]. The point defects induced by neutron bombardment can recombine or form lattice defects of higher dimensionality after the displacement cascade, depending on the irradiation temperature. This defect activity alters the number and strength of defect sinks in the microstructure, and consequently the point defect diffusion and solute redistribution. Throughout the years, different studies of the microstructural evolution induced by neutron irradiation have been published for several austenitic steel grades, with a focus on the 300 series of austenitic stainless steels widely employed in the nuclear industry [20-23]. In these steels, neutron bombardment induces the formation of $\frac{a_{0}}{3}\langle 111\rangle$ Frank loops [20,21,24]. They are often reported as 'black-spot' damage at low irradiation temperatures, due to their size being smaller than 2-3nm [25-28]. They grow in diameter with increasing irradiation temperature, and when they reach a size in the range of $\sim 50 \mathrm{~nm}$ to $100 \mathrm{~nm}$, they can unfault forming perfect dislocation loops with a $\frac{a_{0}}{2}\langle 110\rangle$ Burgers vector [21]. Perfect loops are more mobile than Frank loops, and the interaction of those perfect loops with one another may give rise to dislocation networks. Radiation-induced voids [20,29-31], stacking fault tetrahedra (SFT) [32] and radiation-induced, -enhanced or modified precipitates $[20,25,29,33]$ can also be observed in neutron-irradiated austenitic stainless steels.

The microstructural characterisation of the radiation-induced damage evolution is a fundamental step in understanding the mechanisms inducing solute segregation or depletion close to lattice defects in $20 \mathrm{Cr}-25 \mathrm{Ni}$ stainless steel. Traditional RIS modelling in this material did not include the competing effect of other defect sinks in the microstructure that are generated simultaneously during irradiation [34-37]. In this study, we have monitored in-situ 
the early stages of the lattice damage evolution caused by proton bombardment in the microstructure of recrystallized $20 \mathrm{Cr}-25 \mathrm{Ni} \mathrm{Nb}$-stabilized stainless steel, namely at relatively low damage levels from 0.01 to $0.8 \mathrm{dpa}$ and in the temperature range of $420-500^{\circ} \mathrm{C}$, using a transmission electron microscope (TEM) coupled to an ion accelerator [38,39]. In the past, intense proton beams have been used successfully to simulate the neutron damage in other nuclear steel grades with minimal sample activation [40,41], [42]. A limited number of studies have been published regarding the early stages of damage formation in austenitic stainless steels, being predominantly focused on damage levels close and above 1dpa where loop saturation has been reached, and on temperatures relevant instead for Light Water Reactors [21][28]. The selection of the specific irradiation temperatures in this study, namely $420^{\circ} \mathrm{C}, 460^{\circ} \mathrm{C}$ and $500^{\circ} \mathrm{C}$, was based on the fact that AGR cladding material experiences neutron-induced solute redistribution and sensitization in the temperature range from 350 to $520^{\circ} \mathrm{C}$, with a peak effect at $420^{\circ} \mathrm{C}$ [6]. The early formation and evolution of dislocation structures and other lattice defects at relevant environmental AGR conditions is key for a successful RIS modelling campaign, and consequently to inform safety cases for spent fuel storage. The analysis of the local chemical composition profiles at the grain boundaries and other defect sinks of the AGR cladding material will be presented in a companion paper.

\section{Experimental}

The as-received AGR cladding material was in the form of a $55 \mathrm{~cm}$ long tube with transverse ribs on the outer surface. It had an outer diameter of $1.5 \mathrm{~cm}$ and an average wall thickness of $0.4 \mathrm{~cm}$. Its chemical composition is provided in Table 1 . After removing the external ribs, we extracted samples with a size of $2.5 \times 2.5 \mathrm{~cm}^{2}$ and subjected them to a recrystallization annealing treatment at $930^{\circ} \mathrm{C}$ for $40 \mathrm{~min}$ in inert atmosphere, followed by water quenching. The purpose of this heat treatment was to produce a fine dispersion of $\mathrm{Nb}(\mathrm{C}, \mathrm{N})$ in the recrystallized microstructure [9], so that the level of free interstitials $(\mathrm{C}, \mathrm{N})$ in the matrix is 
kept to a minimum and the potential RIS phenomenon is in principle hindered. The heattreated samples were mechanically ground and polished using in the last step a colloidal silica suspension with a particle size of $0.25 \mu \mathrm{m}$. The structural characterization was performed using a FEI Quanta 650 equipped an electron backscattered diffraction (EBSD) detector. The EBSD data processing was performed using the MTEX software [43]. In the EBSD data analysis, the threshold between high-angle and low-angle grain boundaries was $15^{\circ}[44,45]$. We also performed TEM imaging and analysis of the samples using a FEI Tecnai G2 20 microscope equipped with a Gatan CCD camera. In this case, 3mm-diameter TEM discs were extracted from the heat-treated material and electropolished using an electrolyte of 95 vol. \% methanol - 5 vol. $\%$ perchloric acid $(60 \%)$ at a temperature of $-25^{\circ} \mathrm{C}$.

The in-situ proton irradiations were performed at the Microscope and Ion Accelerator for Materials Investigation - 2 system (MIAMI-2 system), located at the University of Huddersfield, UK. The samples were mounted in a high-temperature double-tilt holder and placed inside a $300 \mathrm{kV}$ Hitachi H-9500 TEM with a spatial resolution of $0.14 \mathrm{~nm}$, equipped with a $\mathrm{LaB}_{6}$ electron source and a Gatan OneView digital camera with 16 megapixels and up to 300 fps video. The TEM is installed at the end of a beam line connected to an ion accelerator, capable of producing proton beams with energies up to $350 \mathrm{keV}$. The proton beam enters the microscope chamber at $18.7^{\circ}$ with respect to the electron beam. We used a proton beam energy of $40 \mathrm{keV}$, and the Bragg peak position would be at $\sim 200 \mathrm{~nm}$ from the sample surface exposed to the incoming proton beam, based on SRIM simulations [46]. We chose this proton beam energy because it was successful in simulating the microstructure of neutron-irradiated AGR cladding at $420^{\circ} \mathrm{C}$ (see discussion section). This temperature corresponds to the peak temperature for the RIS phenomenon in AGR steel claddings. We performed three irradiation experiments using equivalent steel samples at the selected temperatures of $420^{\circ} \mathrm{C}, 460^{\circ} \mathrm{C}$ and $500^{\circ} \mathrm{C}$, and at a proton flux of $\sim 8 x 10^{13}$ ions $\cdot \mathrm{cm}^{-2} \cdot \mathrm{s}^{-1}$, 
corresponding to a dose rate of $\sim 2 \cdot 10^{-4} \mathrm{dpa} / \mathrm{s}$. Images were captured on zone during in-situ irradiation. Additionally at selected damage steps we probed other regions of interest in the sample, and also recorded TEM data in two beam condition. After each irradiation, the sample was characterized ex-situ using an FEI Tecnai G2 20 microscope. The invisibility criterion was used to determine the Burgers vector $\vec{b}$ of the observed dislocations, whereas their nature was assessed by the inside-outside contrast method [47]. The loop size and number density were determined using bright-field images. We used as loop diameter the longest dimension, since under some irradiation conditions the dislocation loops observed in the TEM deviates from circular shape. The foil thickness has been derived from the fringes spacing in convergent beam electron diffraction patterns (CBED) [48]. The foil thickness values obtained were in the range of $110-140 \mathrm{~nm}$. These thickness values are lower than the Bragg peak position of the $40 \mathrm{keV}$ proton beam. The damage levels reported in this study correspond to the average values through the sample thickness. Voids present in the microstructure were observed using the out-of-focus imaging technique in bright-field mode [47]. Further analysis of the radiation damage were conducted ex-situ using a FEI Talos F200A TEM/STEM microscope, equipped with a X-FEG field emission source (TEM information limit of $0.12 \mathrm{~nm}$, point resolution of $0.25 \mathrm{~nm}$ and STEM high angle annular dark field resolution of $0.16 \mathrm{~nm}$ ). This microscope was also used to acquire STEM/EDX maps of the second phase particles observed in the as-recrystallised and proton-irradiated specimens, and the recorded data was then processed using the FEI Velox software.

\section{Results}

The steel microstructure after the $40 \mathrm{~min}$ heat treatment at $930^{\circ} \mathrm{C}$ is shown in Fig. 1 . This high-temperature heat treatment followed by water quenching was chosen in order to mimic the stabilising heat treatment performed on the AGR claddings before entering their service life in the reactor core, as briefly explained above. The microstructure obtained is 
characterised by smooth recrystallised grains with an average diameter of $\sim 10 \mu \mathrm{m}$. The inverse pole figure colour map in Fig. 1a reveals that the recrystallised grains do not exhibit a marked preferred orientation. During the heat treatment, a high number of annealing twin boundaries is produced, accounting for $\sim 45 \%$ of the total grain boundary length. In addition, we also observed $\sim 36 \%$ of high angle grain boundaries (with a misorientation angle $\theta \geq 15^{\circ}$ ) and only $\sim 19 \%$ of low angle grain boundaries $\left(\theta<15^{\circ}\right)$. Moreover, a dispersion of fine of second phase particles precipitates heterogeneously in the matrix, both intergranular (Fig. 1c) and intragranular (Fig. 1d), and in many cases forming particle clusters. STEM/EDX confirmed that those particles present in the microstructure after the $930^{\circ} \mathrm{C}$ annealing are $\mathrm{Nb}$ rich (see Fig 2a), and therefore they have identified as $\mathrm{Nb}(\mathrm{C}, \mathrm{N})$. We have also detected larger $\mathrm{Nb}(\mathrm{C}, \mathrm{N})$ particles already present in the as-received material, and often surrounded by a network of dislocation lines; see Fig. 1e. These larger particles are also $\mathrm{Nb}(\mathrm{C}, \mathrm{N})$ and no segregation of other solute elements was detected (see Fig. 2b).

The evolution of the microstructure during proton irradiation at three different temperatures can be followed in Fig. 3. The early stages of radiation-induced lattice damage in this steel are characterised by the presence of dislocation structures at the three irradiation temperatures. However, the evolution of those structures with increasing damage level varies significantly with temperature. At $420^{\circ} \mathrm{C}$, black spots smaller than $2 \mathrm{~nm}$ are visible in the TEM images of the microstructure at $0.03 \mathrm{dpa}$, together with a number of larger faulted Frank loops with a Burgers vector of $\frac{a_{0}}{3}\langle 111\rangle$. These microstructural features dominate the radiation-induced microstructure up to $0.5 \mathrm{dpa}$; see first row of Fig. 3. The size distribution at a damage level of $0.05 \mathrm{dpa}$, considering both the black spots and the Frank loops, is presented in Fig. 4. The average defect size increases from $\sim 9 \mathrm{~nm}$ at $0.03 \mathrm{dpa}$ to $\sim 12 \mathrm{~nm}$ at $0.05 \mathrm{dpa}$, concomitantly with an increase in number density from $8.1 \times 10^{16} \mathrm{~cm}^{-3}$ to $3.2 \times 10^{17} \mathrm{~cm}^{-3}$ respectively, see Fig. 5. At a damage level of $0.1 \mathrm{dpa}$ and higher, the damage in the 
microstructure becomes very dense and uniform, reaching the resolution limit of the imaging technique used during the in-situ observation. For this reason we were not able to characterise the damage at $420^{\circ} \mathrm{C}$ above this damage level. At $0.1 \mathrm{dpa}$, only identifiable defects were taken into account and the loop parameters for 0.1dpa in Fig. 5 may be less accurate than at lower damage levels. Due to the highly dense damage observed in the microstructure at $0.5 \mathrm{dpa}$ and no signs of other types of dislocation structures, we did not proceed with the proton irradiation beyond this damage level at a temperature of $420^{\circ} \mathrm{C}$.

At higher irradiation temperatures, a longer incubation period or critical damage level is required for the first signs of radiation damage to be observed in the microstructure; see middle and bottom rows in Fig. 3. The first black spots are visible at $0.05 \mathrm{dpa}$ both at $460^{\circ} \mathrm{C}$ and $500^{\circ} \mathrm{C}$, in contrast with $0.03 \mathrm{dpa}$ at $420^{\circ} \mathrm{C}$. Furthermore, the first resolvable Frank loops are observed at $0.1 \mathrm{dpa}$ at $460^{\circ} \mathrm{C}$ and at $0.2 \mathrm{dpa}$ at $500^{\circ} \mathrm{C}$, respectively, together with a number of unfaulted $\frac{a_{0}}{2}\langle 110\rangle$ loops already present at somewhat lower damage levels. Examples of the defect size distribution at representative damage levels at $460^{\circ} \mathrm{C}$ and $500^{\circ} \mathrm{C}$ are shown in Fig. 4, and the average loop diameter and number density as a function of damage level are show in Fig. 5. Comparatively at the same damage level, the lattice defects become larger and less dense with increasing irradiation temperature. Moreover, the average diameter increases steadily with damage level at $460^{\circ} \mathrm{C}$, reaching saturation at $0.8 \mathrm{dpa}$. In contrast, at $500^{\circ} \mathrm{C}$ a plateau is reached in the average size already at $0.2 \mathrm{dpa}$, after a rapid increase from $\sim 14 \mathrm{~nm}$ to $\sim 76 \mathrm{~nm}$ between $0.05 \mathrm{dpa}$ and $0.2 \mathrm{dpa}$. At this damage level, dislocation networks appear in the microstructure and gradually replace the dislocation loops as the main feature of radiation-induced damage. At $460^{\circ} \mathrm{C}$ this transition from loops into networks is delayed to higher damage levels. At this lower temperature and a damage level of $0.8 \mathrm{dpa}$, loop saturation is reached, and a few dislocation tangles start to form. However, the dislocation loops remain the main feature of the radiation-induced damage. The ratio between unfaulted 
and faulted loops remains close to $\sim 0.8$ at $460^{\circ} \mathrm{C}$ and at $0.8 \mathrm{dpa}$ faulted Frank loops are still observed in the damaged microstructure. However, at $500^{\circ} \mathrm{C}$ that ratio is not constant, but decreases at increasing dose from $\sim 0.9$ at $0.2 \mathrm{dpa}$ to $\sim 0.4$ at $0.5 \mathrm{dpa}$ when a significant dislocation network is observed in the TEM images.

Fig. 6 displays examples of radiation-induced dislocation loops at $460^{\circ} \mathrm{C}$ and $500^{\circ} \mathrm{C}$, together with other lattice defects observed in the microstructure at relatively high damage levels. At $460^{\circ} \mathrm{C}$ the loops are relatively small and often present geometrical shapes, such as hexagons and rhombuses. Those loops evolve in less regular shapes at higher damage levels. Besides that, edge-on loops (green arrows in Fig. 6b) and black spots are observed during the whole range of damage levels explored. The edge-on loops present their habit plane parallel to the direction of the electron beam, and they are therefore observed on BF TEM images as lines, instead of close circuits. At $500^{\circ} \mathrm{C}$, the dislocation loops are mainly circular or elliptical in shape, and in some cases small loops are observed to form and grow inside larger loops. Additionally, radiation-induced voids have been observed both at $460^{\circ} \mathrm{C}$ and $500^{\circ} \mathrm{C}$ in this study, but not at $420^{\circ} \mathrm{C}$. The average void diameter increases with temperature from $\sim 3.7 \mathrm{~nm}$ (distribution standard deviation of $1 \mathrm{~nm}$ ) to $\sim 6.1 \mathrm{~nm}$ (distribution standard deviation of $1.5 \mathrm{~nm}$ ) at $0.8 \mathrm{dpa}$, whereas the number density decreases from $6.3 \cdot 10^{15} \mathrm{~cm}^{-3}$ to $4.0 \cdot 10^{15} \mathrm{~cm}^{-3}$, respectively. At $500^{\circ} \mathrm{C}$ stacking fault tetrahedra (SFT) are also observed in the microstructure. They are characterised at $0.8 \mathrm{dpa}$ by an average diameter of $\sim 32 \mathrm{~nm}$, with a standard deviation of $6 \mathrm{~nm}$, and a number density of $9.2 \cdot 10^{13} \mathrm{~cm}^{-3}$.

Local changes in chemical composition were detected at grain boundaries, dislocations and particle/matrix interfaces at the three irradiation temperatures at the highest damage level of this experiment, namely $0.5 \mathrm{dpa}$ at $420^{\circ} \mathrm{C}$, and $0.8 \mathrm{dpa}$ at both $460^{\circ} \mathrm{C}$ and $500^{\circ} \mathrm{C}$. For all those types of defect sinks, we observed the depletion of $\mathrm{Cr}, \mathrm{Fe}$ and to a lower 
extend of $\mathrm{Mn}$, together with the local enrichment in $\mathrm{Ni}$ and $\mathrm{Si}$. The results of the chemical characterisation close to lattice defects will be presented in a companion paper.

\section{Discussion}

The defect evolution and resultant morphologies induced by proton bombardment in $20 \mathrm{Cr}$ $25 \mathrm{Ni} \mathrm{Nb}$-stabilized stainless steel depend on the selected irradiation temperature. At $420^{\circ} \mathrm{C}$, the microstructure observed by TEM up to a damage level of $0.5 \mathrm{dpa}$ is characterized by a high density of black spots and a number of $\frac{a_{0}}{3}\langle 111\rangle$ Frank loops. The radiation-induced damage develops at the relatively low damage level of $0.03 \mathrm{dpa}$ and reaches saturation at only $0.1 \mathrm{dpa}$. The damage evolution at $420^{\circ} \mathrm{C}$ in this steel grade resembles the microstructure reported for other solution-annealed stainless steels irradiated with neutrons at temperatures below $300^{\circ} \mathrm{C}[20,21,49]$. The radiation-induced microstructure, both in the present study and in the case of neutron irradiation, is dominated by the so-called black spots. They are small defect clusters which cannot be resolved in diffraction contrast mode in TEM. They can be both clusters of vacancies, interstitials or impurities, or already well-defined voids or dislocation loops of either nature [22,28,32]. Although in the past these black spots were thought to be predominately of vacancy nature [25-27], more recent studies suggest that they are a mixture of very small vacancy and interstitial Frank loops [28], [50].

At the higher irradiation temperatures of $460^{\circ} \mathrm{C}$ and $500^{\circ} \mathrm{C}$, the microstructure is characterized by the presence of a mixed population of faulted interstitial $\frac{a_{0}}{3}\langle 111\rangle$ Frank loops and unfaulted $\frac{a_{0}}{2}\langle 110\rangle$ dislocation loops, formed after an incubation period or critical damage level. In this temperature range, both types of dislocation loops originate from the growth of clusters of self-interstitial atoms. In fcc materials two cluster configurations of selfinterstitial atoms are possible: $\langle 100\rangle$ dumbbells and $\langle 110\rangle$ crowdions [13]. Once formed, both types of dislocation loops grow with increasing damage level; see loop labelled 'A' in 
Fig. 7. When the Frank loops reached a critical size, they can transform into unfaulted loops. A necessary condition for the unfaulting reaction to take place is the decrease of the loop energy. Based on the energy associated with the two different loop configurations, i.e. faulted and unfaulted, we obtain the following inequality [24]:

$\gamma_{S F E}>\frac{\mu b^{2}}{3 \pi r_{l}}\left[\frac{2-v}{2(v-1)}\right] \ln \left\{\frac{4 r_{l}}{r_{c}}-2\right\}$

where $\gamma_{S F E}\left(35 \mathrm{mJm}^{-2}\right)$ is the stacking fault energy, $\mu(82 \mathrm{GPa})$ is its shear modulus, $b$ $(0.2 \mathrm{~nm})$ is the modulus of the Burgers vector associated with the Frank loop, $r_{l}$ is the radius of the dislocation loop, $v(0.3)$ is the Poisson ratio and $r_{c}(0.5 \mathrm{~nm})$ is the radius of the dislocation core. The data in parenthesis for the aforementioned parameters in the case of stainless steel are taken from ref. [51]. Solving eq. (1) for the loop radius $r_{l}$, we obtained that the minimum loop radius for the faulted-to-unfaulted reaction is $\sim 80 \mathrm{~nm}$. Therefore, the reaction is only energetically favorable for loops whose diameter is $\sim 160 \mathrm{~nm}$ or higher, most likely limited by the sample thickness in one of the loop dimensions. In this study, we found significant percentages of loops that satisfy this condition only at $500^{\circ} \mathrm{C}$, e.g. $12 \%$ at $0.3 \mathrm{dpa}$. Moreover, in order for the reaction to happen, Frank $\frac{a_{0}}{3}[111]$ faulted loops must react with Shockley $\frac{a_{0}}{6}[11 \overline{2}]$ partial dislocations. Therefore, the unfaulting sequence would be [52]:

$$
\frac{a_{0}}{6}[11 \overline{2}]+\frac{a_{0}}{3}[111]=\frac{a_{0}}{2}[110]
$$

The Shockley partial dislocation must nucleate within the Frank dislocation loops for the reaction to occur. Due to the energy condition and the need for Shockley partial nucleation, the faulted-to-unfaulted reaction has seldom been observed in the in-situ irradiation experiments discussed in this paper. An example of this process taking place at $500^{\circ} \mathrm{C}$ is shown in Fig. 7, where loop B with a diameter of $\sim 190 \mathrm{~nm}$ at 0.25 dpa unfaults when 
increasing the damage level to $0.29 \mathrm{dpa}$. In contrast, the ratio between unfaulted and faulted loops remains constant at $460^{\circ} \mathrm{C}$ during the whole irradiation. The fraction of observed Frank loops that undergo an unfaulting process is only $\sim 3 \%$ at $500^{\circ} \mathrm{C}$, and it was not observed at lower temperatures.

Furthermore, perfect dislocation loops can evolve into lines with increasing dose. Perfect loops and especially dislocation lines are glissile, and can move more easily than the sessile Frank loops [53]. The movement of dislocations leads to the occurrence of dislocation tangles, which constitute the last stage of radiation damage evolution in austenitic stainless steels $[20,21,40]$. The formation of tangles or networks occurs both at $460^{\circ} \mathrm{C}$ and $500^{\circ} \mathrm{C}$, as shown as an illustrative example in Fig. 8 for the damage level of 0.8dpa. A higher damage level is required for the dislocation lines to appear in the microstructure at $460^{\circ} \mathrm{C}$, and even at 0.8dpa only a reduced number of dislocation lines can be observed amongst the loops (see Fig. 8). At $500^{\circ} \mathrm{C}$ the first dislocation lines are already visible at $0.2 \mathrm{dpa}$, when the average loop diameter attains saturation at $\sim 76 \mathrm{~nm}$. At this higher temperature, the ratio between unfaulted and faulted loop decreases with the increasing damage level beyond $0.2 \mathrm{dpa}$, due to the transition of a larger number of perfect loops into dislocation lines. Furthermore, the dislocation network formed from the mobile dislocation lines constitute an additional sink for self-interstitial atoms [21], therefore limiting the formation of new dislocation loops and the resultant loop number density at higher damage levels. The average loop size saturates at $\sim 76 \mathrm{~nm}\left(500^{\circ} \mathrm{C}\right)$ and $\sim 50 \mathrm{~nm}\left(460^{\circ} \mathrm{C}\right)$, and saturation coincides with the transition of unfaulted loops into lines/networks. A segment of the loops may escape from the sample surface during the irradiation. However, the average loop size at saturation at both temperatures is significantly smaller than the estimated sample thickness of 110-140nm. Therefore, a significant fraction of the loops would transform into lines before they reach the sample 
surface. Besides that, the loop $\rightarrow$ line transition has also been reported in neutron-irradiated specimens, as mentioned in the introduction section.

Besides the formation of dislocation structures induced by proton bombardment, voids have also been observed at $0.8 \mathrm{dpa}$ for $460^{\circ} \mathrm{C}$ and $500^{\circ} \mathrm{C}$, see Fig. 6 . The average void size increases with irradiation temperature, whereas their number density decreases. In contrast, voids are not observed in the irradiated microstructure at $420^{\circ} \mathrm{C}$ in the studied range of damage levels. The presence of voids has been reported in other austenitic steel grades irradiated with neutrons at temperatures above $300^{\circ} \mathrm{C}$ [20,29,30], [31]. Supersaturation of vacancies is known to be the driving force for void nucleation and growth [13], and different nucleation mechanisms have been proposed, such as nucleation on pre-existing sites in the microstructures, formed directly in the displacement spikes and even via homogeneous nucleation [31]. Voids are not stable below a critical size [54] and would shrink by vacancy emission [55]. During neutron irradiation He atoms can formed by nuclear transmutation from nickel $[18,19]$. The presence of transmuted or implanted gas atoms, such as $\mathrm{He}$ or $\mathrm{H}$, are reported to help stabilise small voids against their collapse into vacancy loops at the very early stages in void formation and swelling [29]. In the present study, no He implantation has been performed or produced by transmutation reactions, and the predicted Bragg peak position of the proton beam (200nm) exceeds the thickness of the TEM foils used (110$140 \mathrm{~nm})$. At $460^{\circ} \mathrm{C}$ and $500^{\circ} \mathrm{C}$ formation of perfect interstitial loops, and their evolution into a high density of dislocation lines, precede the formation of voids. Fig. 6 displays examples of voids having formed close to dislocation lines at $460^{\circ} \mathrm{C}$, and close to a twin boundary at $500^{\circ} \mathrm{C}$. These two lattice defects would absorb interstitial atoms preferentially, yielding a local supersaturation of vacancies in the matrix to form voids [56]. The void distribution at $500^{\circ} \mathrm{C}$ is more homogeneous than at $460^{\circ} \mathrm{C}$, and a small number of square-shaped voids are also observed at $500^{\circ} \mathrm{C}$ (see blue circle in Fig 6g). 
At the highest irradiation temperature, i.e. $500^{\circ} \mathrm{C}$, stacking fault tetrahedra are also observed at $0.8 \mathrm{dpa}$, but in a relatively low number density with respect to the other radiationinduced defects, see Fig. 6h. SFTs are composed of intrinsic on the fo on the $\{111\}$ planes with a stair-rod $\frac{a_{0}}{6}\langle 110\rangle$ dislocation along the edges of the tetrahedron [57]. Based on energy theoretical calculations [58], SFTs should be the most stable vacancy-cluster morphology in stainless steel up to 4000 vacancies. The presence of SFTs in the microstructure of model Febased alloys has been reported in the literature, both at irradiation temperatures lower than $300^{\circ} \mathrm{C}[59]$ and higher than $550^{\circ} \mathrm{C}[60,61]$, where they compete with voids as the dominant intrinsic lattice defect [32]. However, SFTs have been very rarely observed in commercial grade austenitic stainless steels [62], probably due to the presence of impurities and other alloying elements in small quantities that can strongly affect the stacking fault energy (SFE) [63] and also change the evolution of the displacement cascade by binding with vacancies [64]. Various nucleation mechanisms have been proposed throughout the years for SFTs produced during irradiation [32]: SFTs can originate from the dissociation of vacancy-type Frank loops [65], or from small triangular-shaped vacancy nuclei by vacancy absorption [66], through a mechanism of void collapse [67], or directly in the displacement cascade as proposed by [20,21] and confirmed by molecular dynamic simulations [50,68], [69]. The absence of SFTs at $420^{\circ} \mathrm{C}$ and $460^{\circ} \mathrm{C}$ in the present study may be due to the lack of vacancy supersaturation in the matrix, due to the fact that voids are formed preferentially. At $500^{\circ} \mathrm{C}$, dislocation tangles appear already at $0.2 \mathrm{dpa}$ and they absorb interstitials preferentially, loading to a higher vacancy concentration in the matrix than at $460^{\circ} \mathrm{C}$, which can evolve into voids or SFTs. It has to be pointed out that the SFT observed in this study are significantly larger than those reported for other irradiated austenitic stainless steel grades. The average dimension is $\sim 32 \mathrm{~nm}$ with a standard deviation of the size distribution of $6 \mathrm{~nm}$, against an average dimension of around $10 \mathrm{~nm}$ reported in the literature [30]. An average SFT size of 
$20 \mathrm{~nm}$, with a maximum size approaching $30 \mathrm{~nm}$, has been measured in a model austenitic alloy irradiated with neutrons at $550^{\circ} \mathrm{C}$ and $600^{\circ} \mathrm{C}$ (peak exposure of $4.7 \mathrm{dpa}$ ) [52]. In the present study, the absence of SFT smaller than $25 \mathrm{~nm}$ might indicate that these type of defects do not nucleate continuously in $20 \mathrm{Cr}-25 \mathrm{Ni}$ austenitic stainless steel at $500^{\circ} \mathrm{C}$. This observation seems to preclude the direct nucleation in the displacement cascade, in favor of the nucleation by vacancy clustering after supersaturation of vacancies has been generated in the matrix. However, we cannot exclude that SFTs form by the dissociation of vacancy-type Frank loops [65].

The direct comparison of the results obtained in our in-situ proton irradiation experiment with those obtained by in-reactor neutron irradiation is particularly challenging for $20 \mathrm{Cr}-25 \mathrm{Ni} \mathrm{Nb}$-stabilised stainless steel, due to the limited and fragmented nature of the neutron data available. The majority of neutron irradiation studies are primarily focused on the RIS detection and quantification [6,10,70-73], and unfortunately only limited data is available about the lattice defects induced by neutron irradiation [6,10], despite their importance in understanding and predicting RIS profiles in AGR cladding materials. In Fig. 9, we compare our proton irradiation results with the existing data on the neutron-induced microstructure of this steel at the relatively low damage level of 2.2dpa. At this damage level, significant corrosion attacks were detected at the grain boundaries of the matrix after perfoming an accelerated Strauss test [6]. The neutron-induced dislocation density reported for the temperature of $418^{\circ} \mathrm{C}$ is $4 \cdot 10^{14} \mathrm{~m}^{-2}$ [6], which is very close to the dislocation density measured in this study at $0.2 \mathrm{dpa}$ at $460^{\circ} \mathrm{C}$. Unfortunately, the dislocation density was not reported for the sample irradiated with neutrons at $460^{\circ} \mathrm{C}$ at a damage level of $2.2 \mathrm{dpa}$ [10]. However, its microstructure does not resemble the one observed in this study for a protonirradiated sample at $500^{\circ} \mathrm{C}$ and a damage level of $0.4 \mathrm{dpa}$. A shift in temperature has been proposed in the literature to compensate the difference in dose rate between neutron and 
proton irradiations, for an equivalent damage level (assuming a recombination-dominated steady state), according to the expression [74]:

$$
T_{2}=T_{1}+\frac{\frac{k_{B} T_{1}^{2}}{E_{m}^{v}+2 E_{f}^{v}} \ln \left\{\frac{\phi_{2}}{\phi_{1}}\right\}}{1-\frac{k_{B} T_{1}}{E_{m}^{v}+2 E_{f}^{v}} \ln \left\{\frac{\phi_{2}}{\phi_{1}}\right\}}
$$

where $T_{2}$ is the proton irradiation temperature, $T_{1}$ is the neutron irradiation temperature, $k_{B}$ is the Boltzmann constant, $\phi_{2}$ is the proton dose rate $\left(\sim 2 \cdot 10^{-4} \mathrm{dpa} / \mathrm{s}\right.$ in this study $), \phi_{1}$ is the neutron dose rate $\left(4 \cdot 10^{-8} \mathrm{dpa} / \mathrm{s}\right.$ in AGR reactors [37]), $E_{m}^{v}$ is the vacancy migration energy (1.3eV [13]), and $E_{f}^{v}$ the vacancy formation energy (1.9 eV [13]). In this case, Eq. (3) predicts a temperature shift from $418^{\circ} \mathrm{C}$ to $500^{\circ} \mathrm{C}$ and from $460^{\circ} \mathrm{C}$ to $630^{\circ} \mathrm{C}$, in order to compensate for the difference in approx. four orders of magnitude in dose rate for the same damage level. Our comparative results indicate that a higher temperature would be needed in proton irradiations, in order to compare with the damage induced by neutron irradiations, but at lower damage levels. With the present $40 \mathrm{keV}$ proton irradiation experiment we were able to replicate the damaged microstructure of those AGR claddings most affected by RIS after inreactor neutron irradiation $\left(\sim 2 \mathrm{dpa}\right.$ at $\left.\sim 420^{\circ} \mathrm{C}\right)$ by proton irradiation at $460^{\circ} \mathrm{C}$ for a damage level of $0.2 \mathrm{dpa}$, and also the damaged microstructures reported at low temperatures in other austenitic steel grades by selecting an irradiation temperature of $420^{\circ} \mathrm{C}$. , However, we could not replicate the expected temperature shift. This might be due to the differences in the recoil spectra between low-energy light ions such as the proton beam used and the fission neutrons present in the reactor core [75]. The proton beam used in the present study had an energy of $40 \mathrm{keV}$, hence the majority of the damage is produced by low-energy recoil events [76]. On the other hand, in the case of in-reactor neutron irradiation, nearly all lattice defects are generated in cascade by high-energy recoils [77]. The actual number of defects surviving 
after the cascade cooling phase determines the final damage produced in the crystalline structure [13]. Defects produced in relatively large clusters, as in the case of neutron bombardment, have a lower probability to survive the cascade than singularly produced defects. The higher efficiency in the damage production of protons may therefore be the reason behind the fact that we observed a similar proton-damaged microstructure to the reported neutron-induced microstructures in the AGR cladding steel, but at a lower damage level.

\section{Conclusions}

We have performed an in-situ proton irradiation of $20 \mathrm{Cr}-25 \mathrm{Ni} \mathrm{Nb}$-stabilised stainless steel at three selected temperatures with increasing damage levels up to $0.8 \mathrm{dpa}$. This austenitic stainless steel is currently being used as fuel cladding in $\mathrm{AGR}$ reactors. At $420^{\circ} \mathrm{C}$, the radiation-induced damage is dominated by black spots and $\frac{a_{0}}{3}\langle 111\rangle$ Frank loops, and saturates at the relatively low damage level of $0.1 \mathrm{dpa}$. In contrast, at $460^{\circ} \mathrm{C}$ and $500^{\circ} \mathrm{C}$ the damaged microstructure is characterised by a mixed population of Frank loops and perfect $\frac{a_{0}}{2}\langle 110\rangle$ loops at low damage levels, which evolve into a dislocation network at $\geq 0.8 \mathrm{dpa}\left(460^{\circ} \mathrm{C}\right)$ and $\geq 0.2 \mathrm{dpa}\left(500^{\circ} \mathrm{C}\right)$, respectively. The radiation-induced dislocation loops present a lower average size and a higher number density at lower irradiation temperatures. The loop saturation is reached at a higher damage level for a lower temperature, and seems to coincide with the occurrence of a dislocation network. The high density of perfect dislocation loops and lines in the form of a network gives rise to a vacancy supersaturation in the matrix, and consequently to the formation of voids and stacking fault tetrahedra in the microstructure.

\section{Acknowledgments}

We acknowledge the Engineering and Physical Sciences Research Council (EPRSC) for providing funding for this project through the DISTINCTIVE grant (EP/L014041/1), and also 
for the development of the MIAMI-2 Facility (EP/M028283/1) and access via the UK

National Ion Beam Centre. We would also like to thank Dr. S. Walters from the National Nuclear Laboratory for providing the starting material.

\section{References}

[1] R.C. Lobb, H.E. Evans, A determination of the chromium concentration for 'healing' layer formation during the oxidation of chromium-depleted 20cr-25ni-nb stainless steel, Corros. Sci. 24 (1984) 385-396. doi:10.1016/0010-938X(84)90065-9.

[2] S. Nategh, P.J. Goodhew, Z.C. Szkopiak, Microstructural stability during creep of a niobium-stabilized austenitic steel, Acta Metall. 29 (1981) 1299-1308. doi:10.1016/0001-6160(81)90021-3.

[3] G. Knowles, The Creep Strength of 20\%Cr- $25 \% \mathrm{Ni}-\mathrm{Nb}$ Steel Containing Controlled Particle Dispersions, Met. Sci. (1977) 117-122.

[4] H.E. Evans, D.A. Hilton, Structure and properties of nitrided stainless steel fuel cladding for use in advanced gas-cooled reactors, Nucl. Energy. 18 (1979) 33-38. https://inis.iaea.org/search/search.aspx?orig_q=RN:10470696 (accessed July 22, 2018).

[5] R.C. Lobb, R.C. Ecob, Creep rupture properties of oxidised 20\% Cr austenitic stainless steels, Mater. Sci. Technol. 6 (1990) 73-80. doi:10.1179/mst.1990.6.1.73.

[6] C. Taylor, The Formation of Sensitised Microstructures during the Irradiation of CAGR Fuel Pin Cladding, in: D.I.R. Norris (Ed.), Radiation-Induced Sensitisation Stainl. Steel, Berkeley Nuclear Laboratories, 1986.

[7] V. Ramaswamy, D.R.F. West, NbC Precipitation in 20\%Cr-25\%Ni-1\%Nb Austenitic Steel, J. Iron Steel Inst. 208 (1970) 391-394.

[8] T. Sourmail, Precipitation in creep resistant austenitic stainless steel, Mater. Sci. Technol. 17 (2001). 
[9] C. Barcellini, S. Dumbill, E. Jimenez-Melero, Isothermal annealing behaviour of nuclear grade 20Cr-25Ni austenitic stainless steel, Mater. Charact. 145 (2018) 303311. doi:10.1016/j.matchar.2018.08.057.

[10] D.I.R. Norris, C. Baker, C. Taylor, J.M. Titchmarsh, Radiation-Induced Segregation in 20Cr/25Ni/Nb Stainless Steel, ASTM STP 1125, 1992.

[11] D.I.R. Norris, C. Baker, J.M. Titchmarsh, Compositionl Profiles at Grain Boundaries in $20 \% \mathrm{Cr} / 25 \% \mathrm{Ni} / \mathrm{Nb}$ Steinless Steel, in: D.I.R. Norris (Ed.), Radiation-Induced Sensitisation Stainl. Steel, Berkeley Nuclear Laboratories, 1987: p. 87.

[12] NDA Corporate report, Oxide Fuels Preferred Option, SMS/TS/C2-OF/001, 2012.

[13] G.S. Was, Fundamentals of Radiation Materials Science: Metals and Alloys, Springer, 2007.

[14] T.R. Allen, G.S. Was, E.A. Kenik, The effect of alloy composition on radiationinduced segregation in Fe/Cr/Ni alloys, J. Nucl. Mater. 244 (1997) 278-294. doi:10.1016/S0022-3115(96)00744-1.

[15] T.R. Allen, J.T. Busby, G.S. Was, E.A. Kenik, On the mechanism of radiation-induced segregation in austenitic Fe--Cr--Ni alloys, J. Nucl. Mater. 255 (1998) 44-58. doi:http://dx.doi.org/10.1016/S0022-3115(98)00010-5.

[16] T.R. Allen, G.S. Was, The effect of ordering on radiation-induced segregation in austenitic iron- and nickel-base alloys, in: Eff. Radiat. Mater. 18th Int. Symp., ASTM, 1999.

[17] K.G. Field, L.M. Barnard, C.M. Parish, J.T. Busby, D. Morgan, T.R. Allen, Dependence on grain boundary structure of radiation induced segregation in a $9 \mathrm{wt} . \%$ Cr model ferritic/martensitic steel, J. Nucl. Mater. 435 (2013) 172-180. doi:10.1016/J.JNUCMAT.2012.12.026.

[18] T.S. Duh, J.J. Kai, F.R. Chen, L.H. Wang, Numerical simulation modeling on the 
effects of grain boundary misorientation on radiation-induced solute segregation in 304 austenitic stainless steels, J. Nucl. Mater. 294 (2001) 267-273.

[19] T.S. Duh, J.J. Kai, F.R. Chen, Effects of grain boundary misorientation on solute segregation in thermally sensitized and proton-irradiated 304 stainless steel, J. Nucl. Mater. 283-287 (2000) 198-204. doi:10.1016/S0022-3115(00)00255-5.

[20] P.J. Maziasz, Overview of microstructural evolution in neutron-irradiated austenitic stainless steels, J. Nucl. Mater. 205 (1993) 118-145. doi:10.1016/00223115(93)90077-C.

[21] S.J. Zinkle, P.J. Maziasz, R.E. Stoller, Dose dependence of the microstructural evolution in neutron-irradiated austenitic stainless steel, J. Nucl. Mater. 206 (1993) 266-286. doi:10.1016/0022-3115(93)90128-L.

[22] S.M. Bruemmer, E.P. Simonen, P.M. Scott, P.L. Andresen, G.S. Was, J.L. Nelson, Radiation-induced material changes and susceptibility to intergranular failure of lightwater-reactor core internals, J. Nucl. Mater. 274 (1999) 299-314. doi:10.1016/S00223115(99)00075-6.

[23] A.F. Rowcliffe, S.J. Zinkle, J.F. Stubbins, D.J. Edwards, D.J. Alexander, Austenitic stainless steels and high strength copper alloys for fusion components, J. Nucl. Mater. 258-263 (1998) 183-192. doi:10.1016/S0022-3115(98)00333-X.

[24] B.T. Kelly, Irradiation damage to solids, 1st ed., Oxford ; New York : Pergamon Press, 1966.

[25] T.S. Byun, E.H. Lee, J.D. Hunn, Plastic deformation in 316LN stainless steel characterization of deformation microstructures, J. Nucl. Mater. 321 (2003) 29-39. doi:10.1016/S0022-3115(03)00195-8.

[26] E.H. Lee, J.D. Hunn, T.S. Byun, L.K. Mansur, Effects of helium on radiation-induced defect microstructure in austenitic stainless steel, J. Nucl. Mater. 280 (2000) 18-24. 
doi:10.1016/S0022-3115(00)00038-6.

[27] N. Hashimoto, E. Wakai, J.P. Robertson, Relationship between hardening and damage structure in austenitic stainless steel 316LN irradiated at low temperature in the HFIR, J. Nucl. Mater. 273 (1999) 95-101. doi:10.1016/S0022-3115(99)00009-4.

[28] D.J. Edwards, E.P. Simonen, S.M. Bruemmer, Evolution of fine-scale defects in stainless steels neutron-irradiated at $275^{\circ} \mathrm{C}$, J. Nucl. Mater. 317 (2003) 13-31. doi:10.1016/S0022-3115(03)00002-3.

[29] T.R. Allen, J.I. Cole, C.L. Trybus, D.L. Porter, H. Tsai, F. Garner, E.A. Kenik, T. Yoshitake, J. Ohta, The effect of dose rate on the response of austenitic stainless steels to neutron radiation, J. Nucl. Mater. 348 (2006) 148-164. doi:10.1016/J.JNUCMAT.2005.09.011.

[30] J.I. Cole, T.R. Allen, Microstructural changes induced by post-irradiation annealing of neutron-irradiated austenitic stainless steels, J. Nucl. Mater. 283-287 (2000) 329-333. doi:10.1016/S0022-3115(00)00072-6.

[31] D.I.R. Norris, Voids in irradiated metals (Part I), Radiat. Eff. 15 (1972) 1-22. https://doi.org/10.1080/00337577208230470.

[32] R. Schibli, R. Schäublin, On the formation of stacking fault tetrahedra in irradiated austenitic stainless steels - A literature review, J. Nucl. Mater. 442 (2013) S761-S767. doi:10.1016/J.JNUCMAT.2013.05.077.

[33] D.J. Edwards, E.P. Simonen, F.A. Garner, L.R. Greenwood, B.M. Oliver, S.M. Bruemmer, Influence of irradiation temperature and dose gradients on the microstructural evolution in neutron-irradiated 316SS, J. Nucl. Mater. 317 (2003) 3245. doi:10.1016/S0022-3115(03)00003-5.

[34] A.D. Marwick, Segregation in irradiated alloys: The inverse Kirkendall effect and the effect of constitution on void swelling, J. Phys. F Met. Phys. 8 (1978) 1849. 
http://stacks.iop.org/0305-4608/8/i=9/a=008.

[35] H. Wiedersich, P.R. Okamoto, N.Q. Lam, A theory of radiation-induced segregation in concentrated alloys, J. Nucl. Mater. 83 (1979) 98-108.

doi:http://dx.doi.org/10.1016/0022-3115(79)90596-8.

[36] S. Watanabe, H. Takahashi, Discriminant of RIS in multi-component alloys, J. Nucl. Mater. 208 (1994) 191-194. doi:10.1016/0022-3115(94)90211-9.

[37] J.M. Perks, A.D. Marwick, C.A. English, Fundamental Aspects of radiation-induced Segregation in Fe-Cr-Ni Alloys, in: D.I.R. Norris (Ed.), Radiation-Induced Sensitisation Stainl. Steel, Berkeley Nuclear Laboratories, 1986.

[38] J.A. Hinks, A review of transmission electron microscopes with in situ ion irradiation, Nucl. Instruments Methods Phys. Res. Sect. B Beam Interact. with Mater. Atoms. 267 (2009) 3652-3662. doi:10.1016/J.NIMB.2009.09.014.

[39] S. Ishino, A review of in situ observation of defect production with energetic heavy ions, J. Nucl. Mater. 251 (1997) 225-236. doi:10.1016/S0022-3115(97)00247-X.

[40] G.S. Was, J.T. Busby, T. Allen, E.A. Kenik, A. Jensson, S.M. Bruemmer, J. Gan, A.D. Edwards, P.M. Scott, P.L. Andreson, Emulation of neutron irradiation effects with protons: validation of principle, J. Nucl. Mater. 300 (2002) 198-216. doi:http://dx.doi.org/10.1016/S0022-3115(01)00751-6.

[41] G.S. Was, T.R. Allen, J.T. Busby, J. Gan, D. Damcott, D. Carter, M. Atzmon, E.A. Kenik, Microchemistry and microstructure of proton-irradiated austenitic alloys: toward an understanding of irradiation effects in LWR core components, J. Nucl. Mater. 270 (1999) 96-114. doi:10.1016/S0022-3115(98)00897-6.

[42] J. Gan, G.S. Was, Microstructure evolution in austenitic $\mathrm{Fe}-\mathrm{Cr}-\mathrm{Ni}$ alloys irradiated with protons: comparison with neutron-irradiated microstructures, J. Nucl. Mater. 297 (2001) 161-175. doi:10.1016/S0022-3115(01)00615-8. 
[43] F. Bachmann, R. Hielscher, H. Schaeben, Texture Analysis with MTEX -- Free and Open Source Software Toolbox, in: Texture Anisotropy Polycrystals III, Trans Tech Publications, 2010: pp. 63-68.

[44] R.E. Stoller, M.B. Toloczko, G.S. Was, A.G. Certain, S. Dwaraknath, F.A. Garner, On the use of $\{$ SRIM $\}$ for computing radiation damage exposure, Nucl. Instruments Methods Phys. Res. Sect. B Beam Interact. with Mater. Atoms. 310 (2013) 75-80. doi:http://dx.doi.org/10.1016/j.nimb.2013.05.008.

[45] M.L. Jenkins, Characterisation of radiation-damage microstructures by TEM, J. Nucl. Mater. 216 (1994) 124-156. doi:http://dx.doi.org/10.1016/0022-3115(94)90010-8.

[46] D. Delille, R. Pantel, E. Van Cappellen, Crystal thickness and extinction distance determination using energy filtered $\{\mathrm{CBED}\}$ pattern intensity measurement and dynamical diffraction theory fitting, Ultramicroscopy. 87 (2001) 5-18. doi:http://dx.doi.org/10.1016/S0304-3991(00)00067-X.

[47] F.J. Humphreys, Quantitative metallography by electron backscattered diffraction, J. Microsc. 195 (1999) 170-185. http://dx.doi.org/10.1046/j.1365-2818.1999.00578.x.

[48] F.J. Humphreys, Review Grain and subgrain characterisation by electron backscatter diffraction, J. Mater. Sci. 36 (2001) 3833-3854. https://doi.org/10.1023/A:1017973432592.

[49] H.R. Brager, J.L. Straalsund, Defect development in neutron irradiated type 316 stainless steel, J. Nucl. Mater. 46 (1973) 134-158. doi:10.1016/0022-3115(73)901311.

[50] R. Stoenescu, R. Schaeublin, D. Gavillet, N. Baluc, Mechanical propertiesmicrostructure correlation in neutron irradiated heat-affected zones of austenitic stainless steels, J. Nucl. Mater. 362 (2007) 287-292. doi:10.1016/J.JNUCMAT.2007.01.251. 
[51] G.S. Was, T.R. Allen, Radiation damage from different particle types, in: B.P.U. Kurt E. Sickafus Eugene A. Kotomin (Ed.), Radiat. Eff. Solids, Springer Netherlands, 2007.

[52] H. Tanigawa, A. Kohyama, Y. Katoh, A modeling of radiation induced microstructural evolution under applied stress in austenitic alloys, J. Nucl. Mater. 239 (1996) 80-84. doi:10.1016/S0022-3115(96)00414-X.

[53] D.J. Hull, Derek \& Bacon, Introduction to dislocations, 5th ed., ButterworthHeinemann, 2011.

[54] K.C. Russell, Nucleation of voids in irradiated metals, Acta Metall. 19 (1971) 753758. doi:10.1016/0001-6160(71)90131-3.

[55] K.C. Russell, Nucleation of voids in irradiated metals. II. The general case, Scr. Metall. 6 (1972) 209-214. doi:10.1016/0036-9748(72)90169-X.

[56] D.I.R. Norris, The growth of voids in nickel in a high-voltage electron microscope, Philos. Mag. A J. Theor. Exp. Appl. Phys. 23 (1971) 135-152. doi:10.1080/14786437108216368.

[57] M. Kiritani, Story of stacking fault tetrahedra, Mater. Chem. Phys. 50 (1997) 133-138. doi:10.1016/S0254-0584(97)80250-7.

[58] S.J. Zinkle, L.E. Seitzman, W.G. Wolfer, S.J. Zinkle, W.G. Wolfer, I. Energy calculations for pure metals, Philos. Mag. A Phys. Condens. Matter, Struct. Defects Mech. Prop. 55 (1987) 111-125. doi:10.1080/01418618708209803.

[59] M. Horiki, S. Arai, Y. Satoh, M. Kiritani, Identification of the nature of small point defect clusters in neutron irradiated $\mathrm{Fe}-16 \mathrm{Ni}-15 \mathrm{Cr}$ by means of electron irradiation, $\mathrm{J}$. Nucl. Mater. 255 (1998) 165-173. doi:10.1016/S0022-3115(98)00033-6.

[60] R.E. Stoller, G.R. Odette, Observations of stacking-fault tetrahedra in an austenitic alloy after high-temperature neutron irradiation, Philos. Mag. A. 58 (1988) 523-532. doi:10.1080/01418618808210428. 
[61] R.E. Stoller, G.R. Odette, The effects of helium implantation on microstructural evolution in an austenitic alloy, J. Nucl. Mater. 154 (1988) 286-304. doi:10.1016/0022-3115(88)90365-0.

[62] Y. Dai, X. Jia, J.C. Chen, W.F. Sommer, M. Victoria, G.S. Bauer, Microstructure of both as-irradiated and deformed 304L stainless steel irradiated with $800 \mathrm{MeV}$ protons, J. Nucl. Mater. 296 (2001) 174-182. doi:10.1016/S0022-3115(01)00565-7.

[63] S. Lu, Q.-M. Hu, B. Johansson, L. Vitos, Stacking fault energies of Mn, Co and Nb alloyed austenitic stainless steels, Acta Mater. 59 (2011) 5728-5734. doi:https://doi.org/10.1016/j.actamat.2011.05.049.

[64] C.A. English, B.L. Eyre, K. Shoaib, T.M. Williams, Vacancy cluster damage in type 316 stainless steel irradiated with Cr+ ions, J. Nucl. Mater. 58 (1975) 220-226. doi:10.1016/0022-3115(75)90110-5.

[65] J. Silcox, P.B. Hirsch, Direct observations of defects in quenched gold, Philos. Mag. 4 (1959) 72-89. doi:10.1080/14786435908238228.

[66] G. Czjzek, A. Seeger, S. Mader, Die Stabilität von Stapelfehlertetraedern in abgeschreckten kubisch-flächenzentrierten Metallen und Legierungen, Phys. Status Solidi. 2 (1962) 558-565. doi:10.1002/pssb.19620020505.

[67] B.P. Uberuaga, R.G. Hoagland, A.F. Voter, S.M. Valone, Direct Transformation of Vacancy Voids to Stacking Fault Tetrahedra, Phys. Rev. Lett. 99 (2007).

[68] K. Nordlund, F. Gao, Formation of stacking-fault tetrahedra in collision cascades, Appl. Phys. Lett. 74 (1999) 2720-2722. doi:10.1063/1.123948.

[69] Z. Yao, M.J. Caturla, R. Schäublin, Study of cascades damage in Ni by MD with different interatomic potentials, J. Nucl. Mater. 367-370 (2007) 298-304. doi:10.1016/J.JNUCMAT.2007.03.136.

[70] M.A. Ashworth, D.I.R. Norris, I.P. Jones, Radiation-Induced Segregation in 
Fe/20Cr/25Ni/Nb Based Austenitic Stainless Steel, J. Nucl. Mater. 189 (1992) 289302.

[71] D.I.R. Norris, C. Baker, J.M. Titchmarsh, A study of radiation-induced sensitusation in 20/25/Nb steel by compositional profile measurements at grain boundaries, in: B.N.E. Society (Ed.), Mater. Nucl. React. Core Appl., 1987.

[72] J.M. Titchmarsh, I.A. Vatter, Measurement of Radiation-induced Segregation Profiles by High Spatial Resolution Electron Microscopy, in: D.I.R. Norris (Ed.), RadiationInduced Sensitisation Stainl. Steel, Berkeley Nuclear Laboratories, 1986.

[73] T.M. Williams, R.M. Boothby, J.M. Titchmarsh, Compositional Redistribution in Irradiated Austenitic Steels and Consequent Changes in Microstructures, in: D.I.R. Norris (Ed.), Radiation-Induced Sensitisation Stainl. Steel, Berkeley Nuclear Laboratories, 1986.

[74] L.K. Mansur, Theory of transitions in dose dependence of radiation effects in structural alloys, J. Nucl. Mater. 206 (1993) 306-323. doi:http://dx.doi.org/10.1016/0022-3115(93)90130-Q.

[75] C. Abromeit, Aspects of simulation of neutron damage by ion irradiation, J. Nucl. Mater. 216 (1994) 78-96. doi:10.1016/0022-3115(94)90008-6.

[76] R.S. Averback, Atomic displacement processes in irradiated metals, J. Nucl. Mater. 216 (1994) 49-62. doi:10.1016/0022-3115(94)90006-X.

[77] L.R. Greenwood, Neutron interactions and atomic recoil spectra, J. Nucl. Mater. 216 (1994) 29-44. doi:10.1016/0022-3115(94)90004-3. 


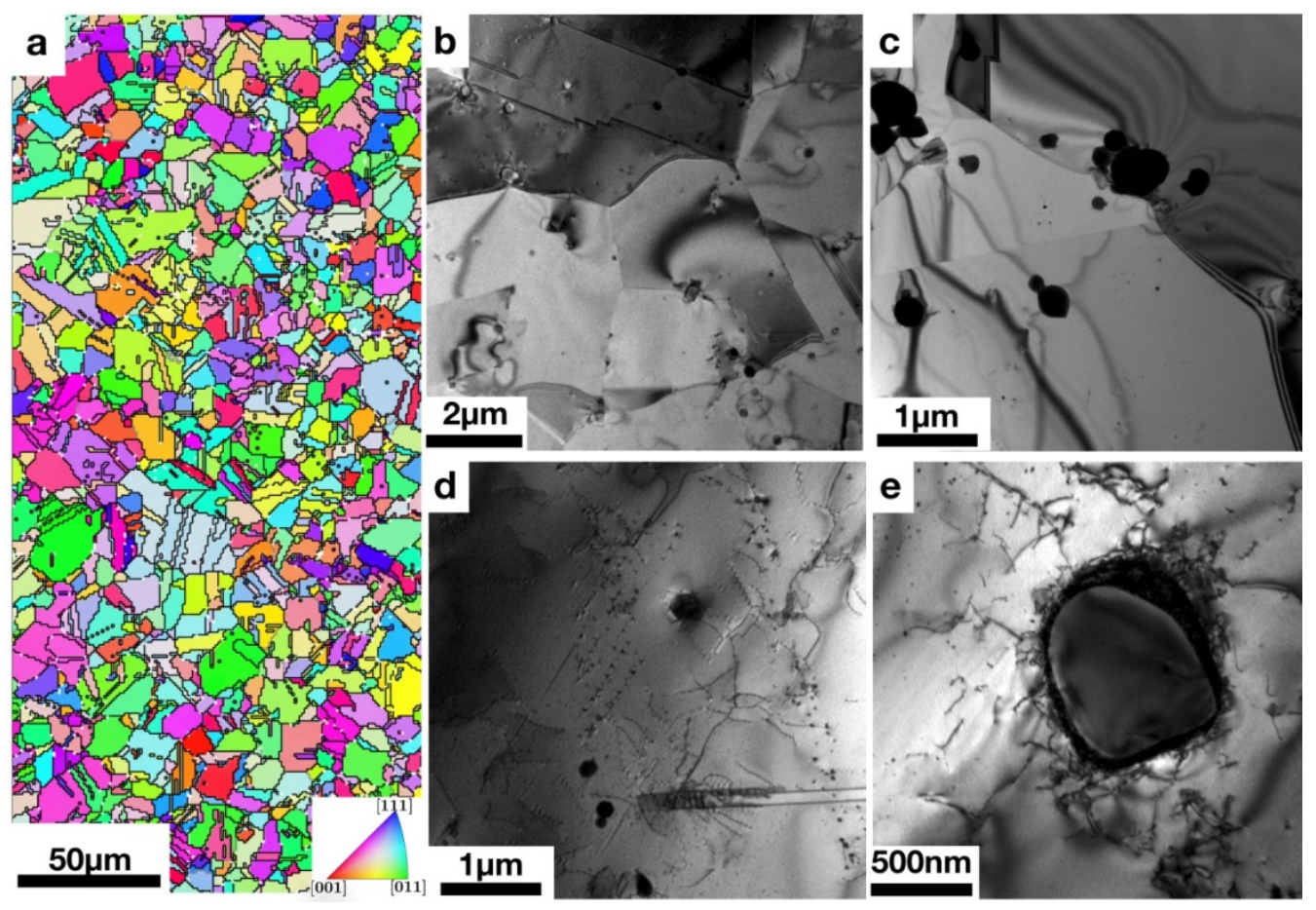

Fig. 1. (a) Inverse pole figure colour map of the as-recrystallized microstructure of $20 \mathrm{Cr}-25 \mathrm{Ni}$ $\mathrm{Nb}$-stabilised steel, together with BF TEM images of (b) smooth recrystallized grains, (c) and (d) clusters of fine $\mathrm{Nb}(\mathrm{C}, \mathrm{N})$ particles, some of them located at a grain boundary, and (e) a large $\mathrm{Nb}(\mathrm{C}, \mathrm{N})$ particle surrounded by a dislocation network and present already in the as-received material. 


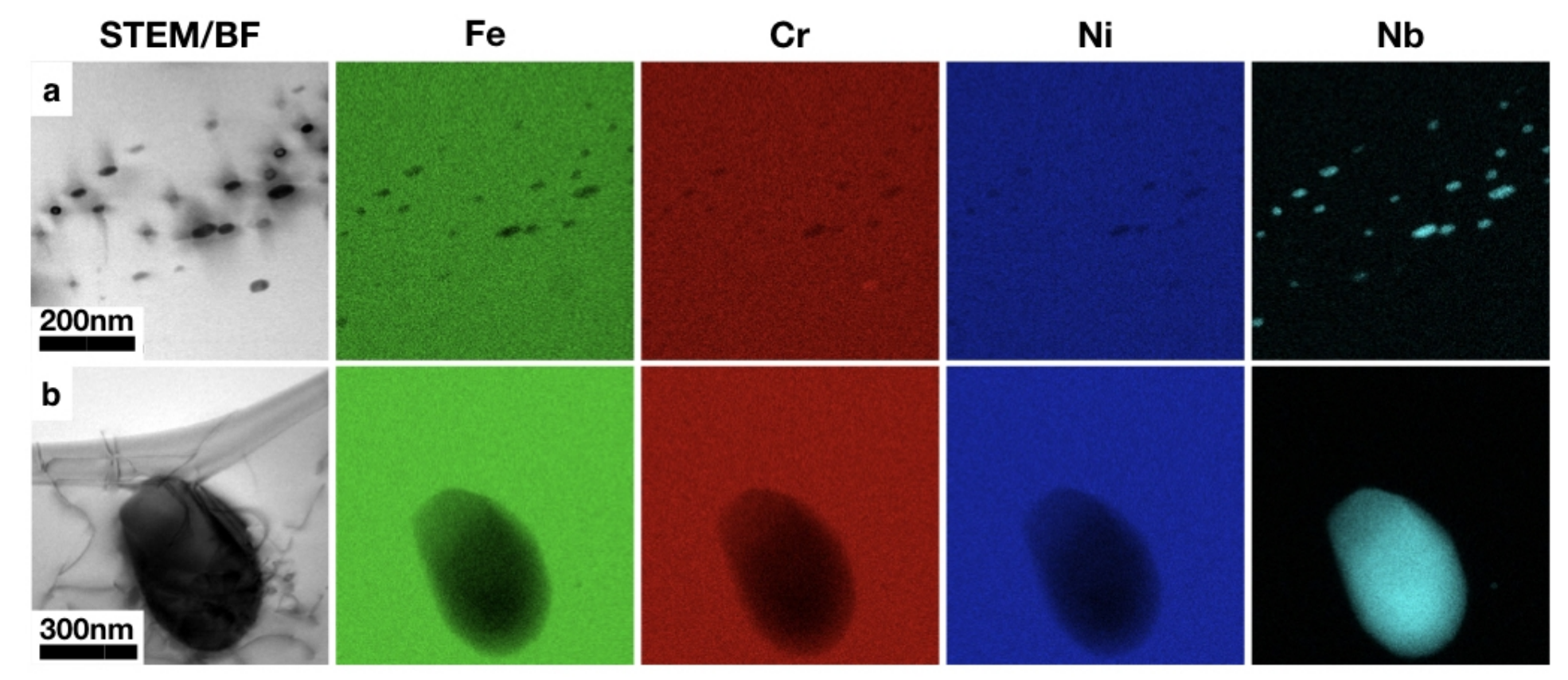

Fig. 2. STEM/EDX chemical maps of (a) a fine dispersion of second phase particles formed during the heat treatment at $930^{\circ} \mathrm{C}$ for $40 \mathrm{~min}$, and (b) a second phase particle already present in the as-received material. 


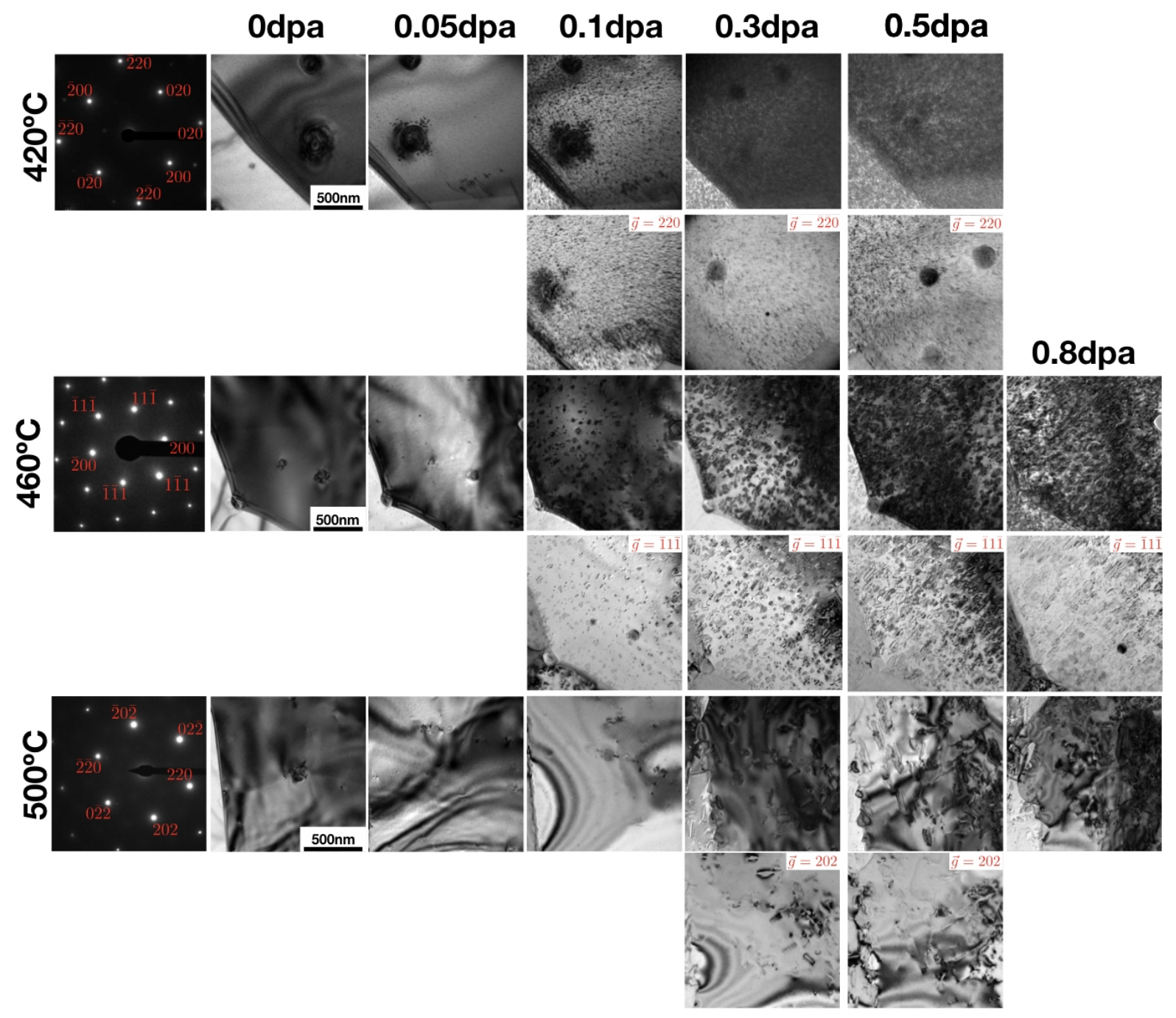

Fig. 3. BF TEM micrographs showing the microstructure evolution during $40 \mathrm{keV}$ proton irradiation at three irradiation temperatures. The images have been acquired with the electron beam parallel to the $[001]$ direction at $420^{\circ} \mathrm{C}$, to the $[011]$ at $460^{\circ} \mathrm{C}$ and to the $[\overline{1} 11]$ at $500^{\circ} \mathrm{C}$. Examples of BF TEM micrographs acquired in a two beam condition are shown for selected damage levels. 


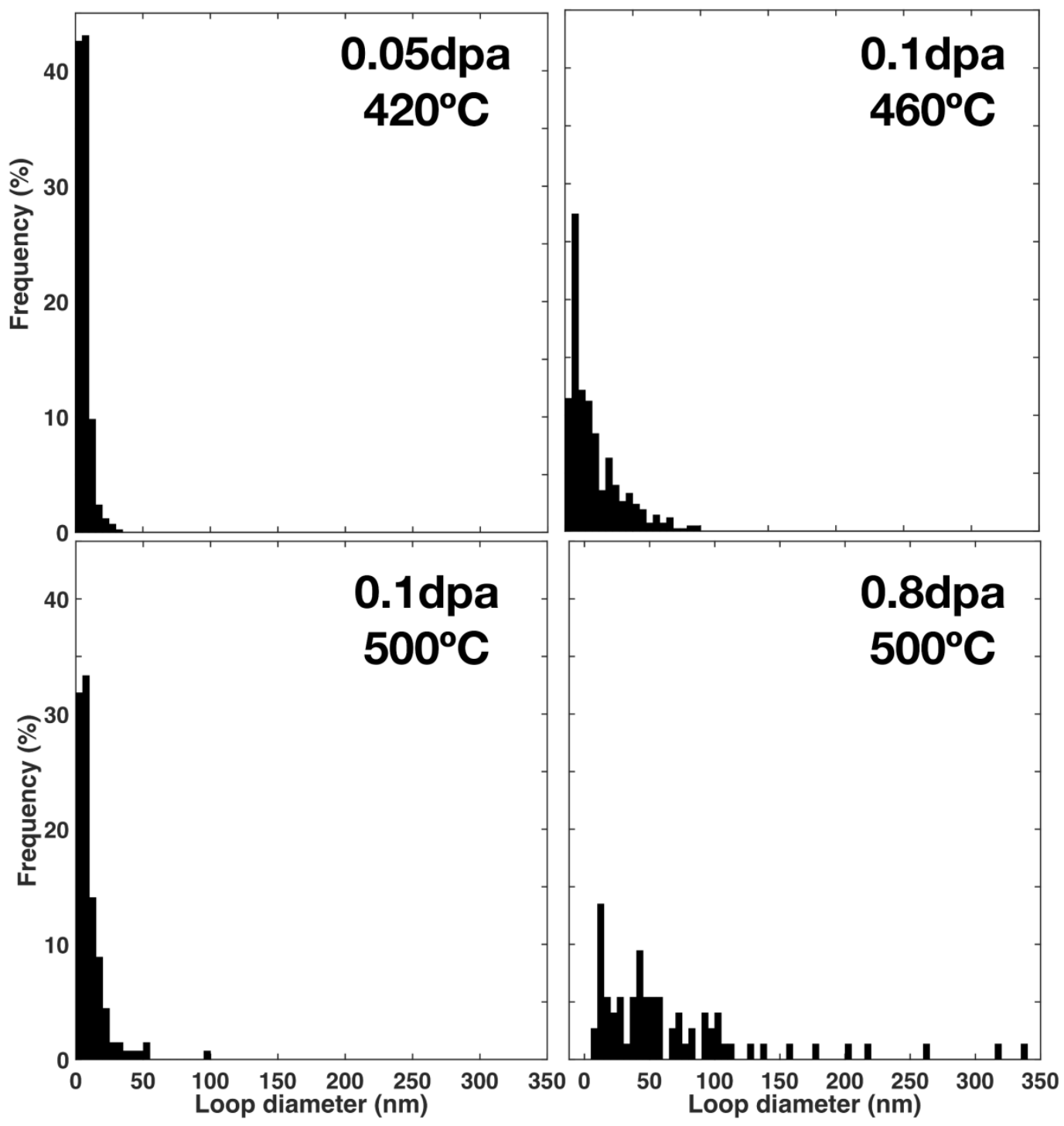

Fig. 4. Loop diameter distribution at representative irradiation temperatures and damage levels. 

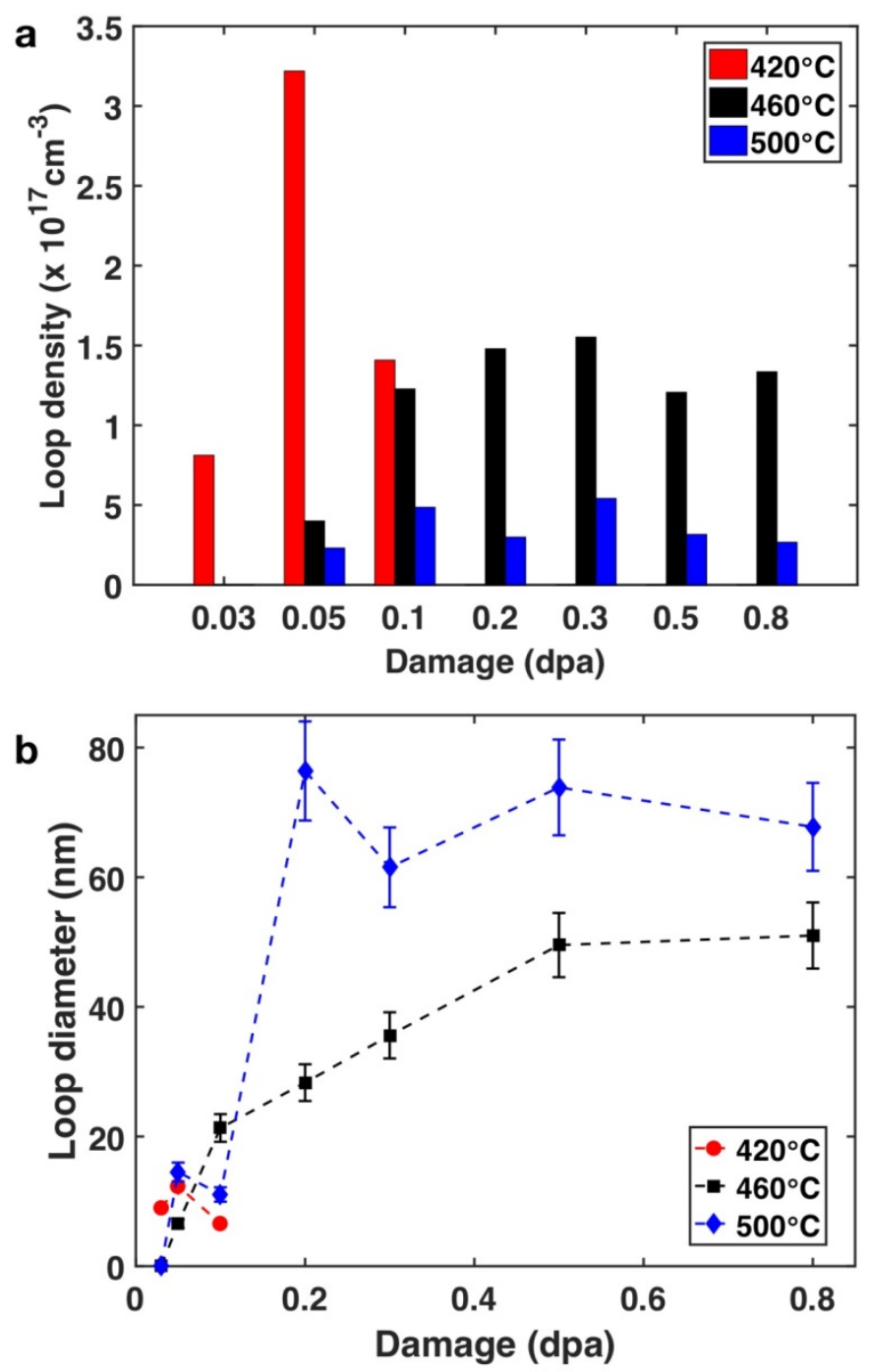

Fig. 5. Evolution of the (a) loop number density and (b) loop diameter with the damage level at three different irradiation temperatures. 


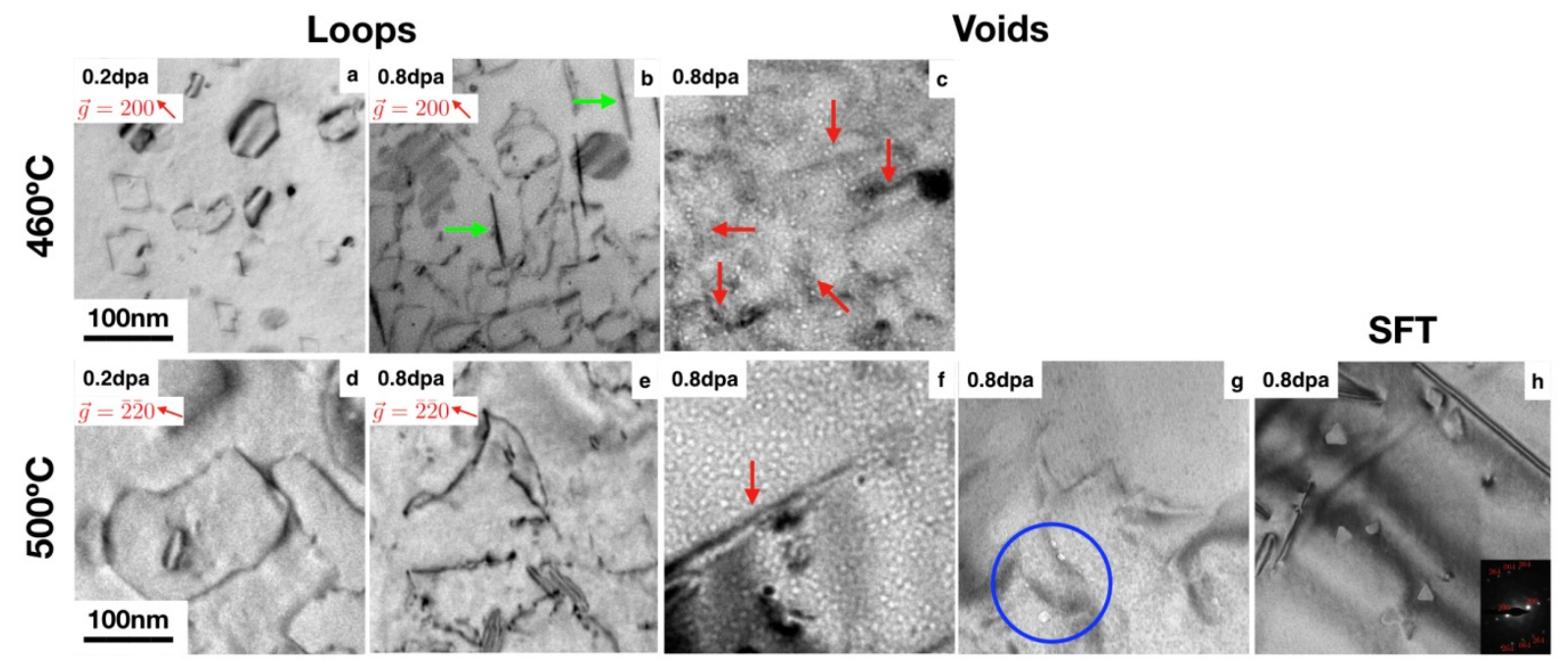

Fig. 6. BF TEM micrographs showing examples of faulted and un-faulted loops in (a), (b) and (d), dislocation lines in (e), voids in (c), (f) and (g), and also stacking fault tetrahedra (SFT) in (h), observed at $460^{\circ} \mathrm{C}$ and $500^{\circ} \mathrm{C}$ at selected damage levels. The defocus in (c) (f) and $(\mathrm{g})$ was of $-500 \mathrm{~nm}$. Examples of edge-on loops are pointed with green arrows in (b), whereas examples voids nucleated in the proximity of dislocations with red arrows in (c). A twin boundary decorated with voids is indicated with a red arrow in (f), whereas voids with rectangular shapes are circled in blue in $(\mathrm{g})$. 


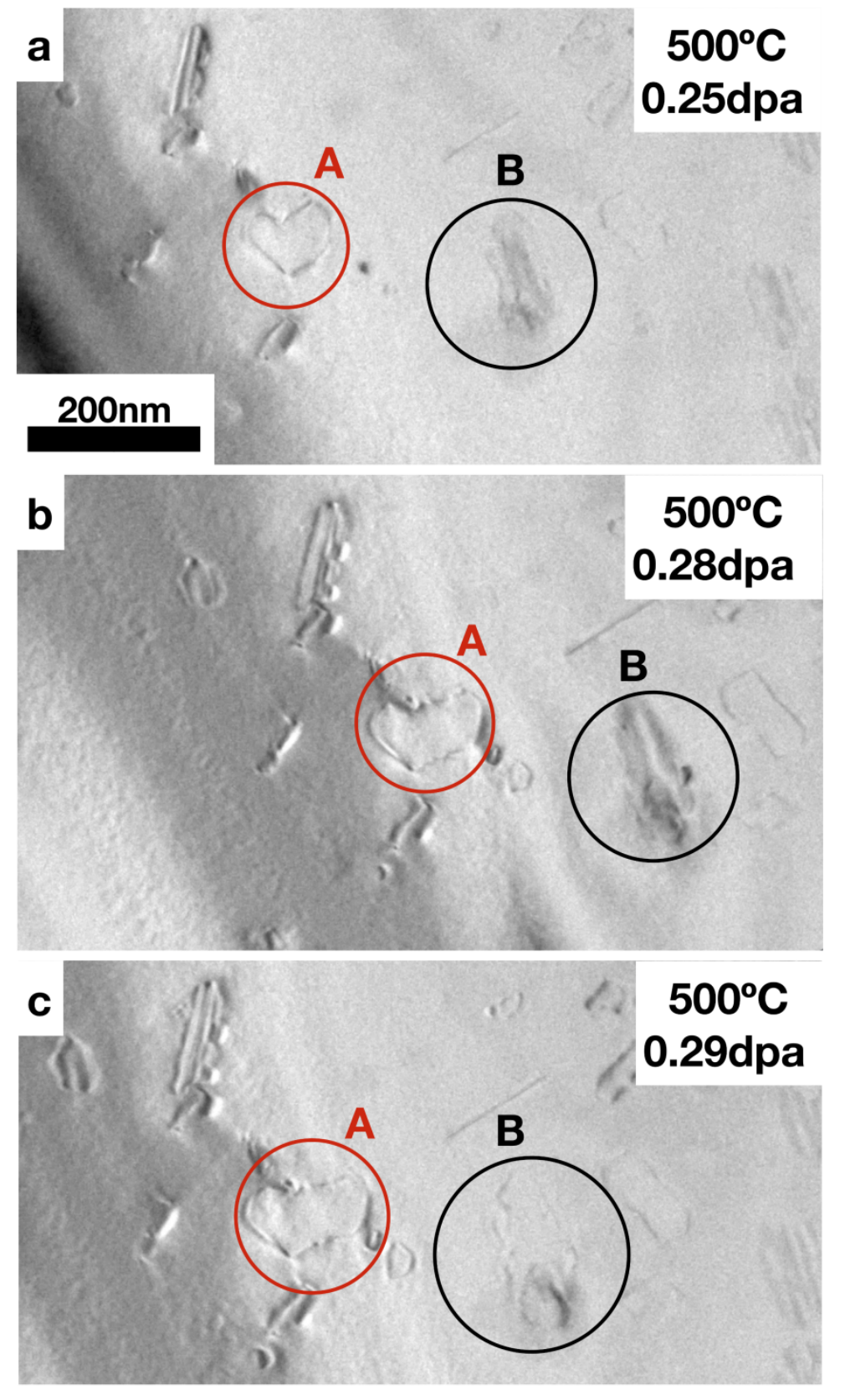

Fig. 7. BF TEM micrographs showing the evolution of representative dislocation loops in the sample irradiated at $500^{\circ} \mathrm{C}$ and at selected damage levels: (a) $0.25 \mathrm{dpa}$, (b) $0.28 \mathrm{dpa}$ and (c) $0.29 \mathrm{dpa}$. 

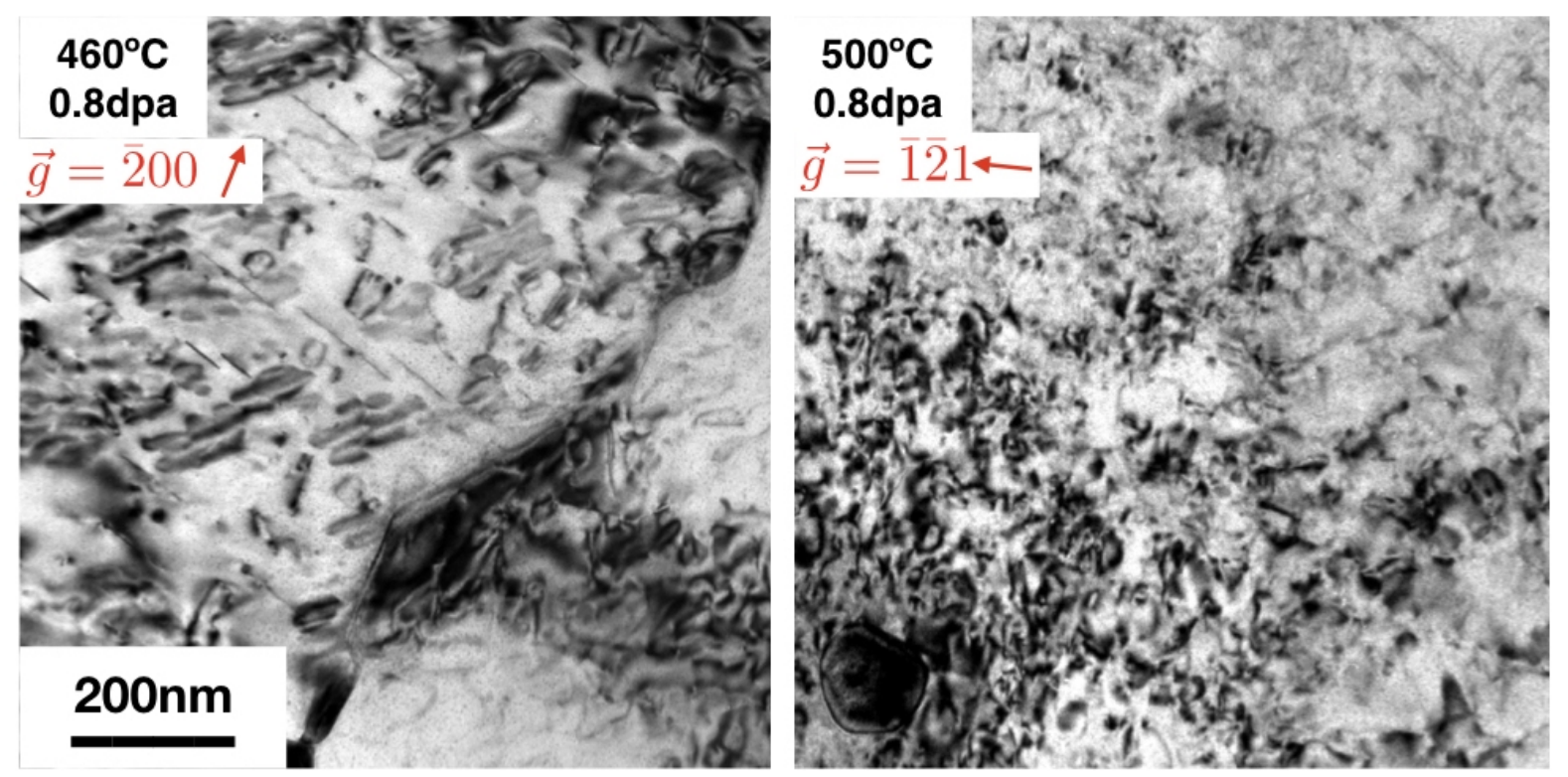

Fig. 8. BF TEM micrographs showing an example of the dislocation network observed at 460 ${ }^{\circ} \mathrm{C}$ and $500^{\circ} \mathrm{C}$. 


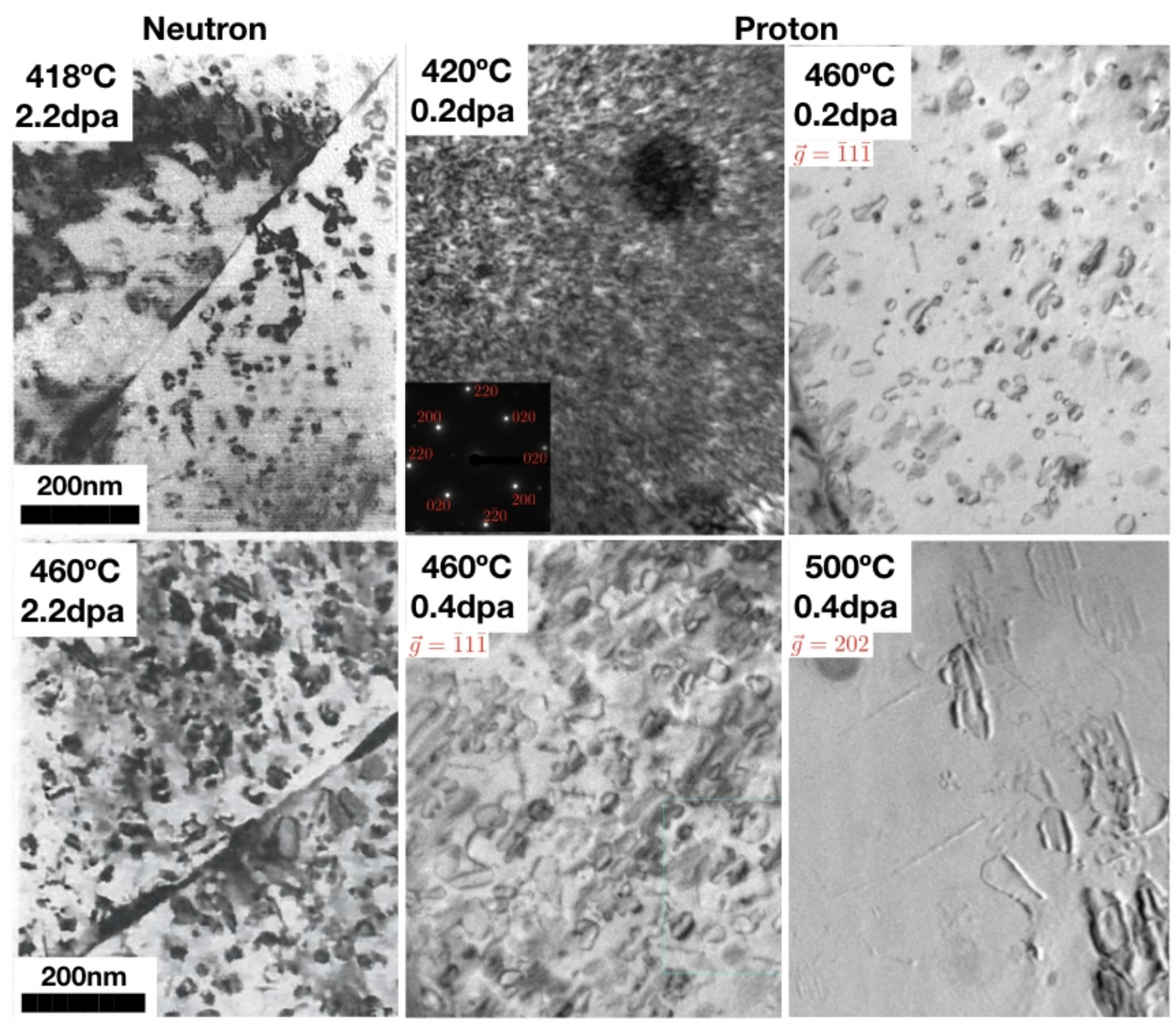

Fig. 9. BF TEM micrographs comparing the proton-irradiated microstructure observed in this study (middle and right columns) with the neutron-irradiated microstructures (left column) reported for $20 \mathrm{Cr}-25 \mathrm{Ni} \mathrm{Nb}$-stabilised stainless steel at relatively low damage levels and at equivalent irradiation temperatures. The neutron data at $418^{\circ} \mathrm{C}$ and $460^{\circ} \mathrm{C}$ are taken from ref.[9] and [6], respectively. 

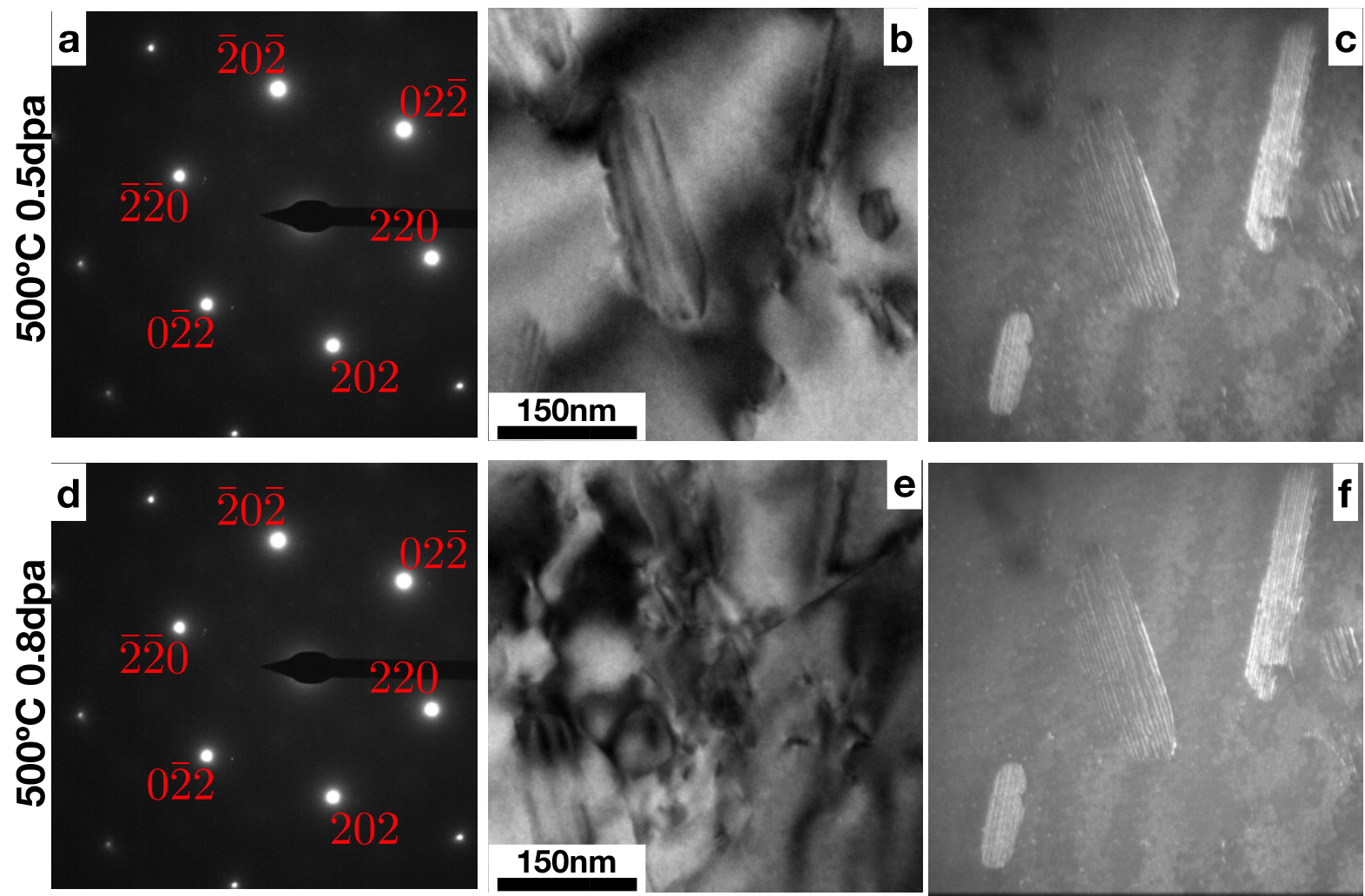

Fig. 1. (a)Examples of the evolution of Frank faulted loops imaged with different techinques. In (a) and (d) on zone diffraction pattern, (b) and (e) on zone BF TEM micrographs and (c) and (f) centred dark field (CDF) micrographs acquired using $02 \overline{2}$ reflection showing the typical fringes of faulted loops. 


\section{Tables}

Table 1. Chemical composition in wt $\%$ of $20 \mathrm{Cr}-25 \mathrm{Ni}$ steel used in this study.

\begin{tabular}{|l|l|l|l|l|l|l|l|l|l|l|l|l|l|l|}
\hline $\mathbf{C}$ & $\mathbf{M n}$ & $\mathbf{S i}$ & $\mathbf{S}$ & $\mathbf{P}$ & $\mathbf{C u}$ & $\mathbf{N i}$ & $\mathbf{C r}$ & $\mathbf{M o}$ & $\mathbf{N b}$ & $\mathbf{V}$ & $\mathbf{A l}$ & $\mathbf{T i}$ & $\mathbf{N}$ & $\mathbf{F e}$ \\
\hline 0.058 & 0.59 & 0.58 & 0.002 & $<0.003$ & $<0.01$ & 23.98 & 19.12 & $<0.01$ & 0.57 & $<0.01$ & 0.017 & 0.01 & 0.009 & Bal. \\
& & & & & & & & & & & & & & \\
\hline
\end{tabular}

